Article

\title{
Fresh-State and Mechanical Properties of High-Performance Self-Compacting Concrete with Recycled Aggregates from the Precast Industry
}

\author{
Tiago Barroqueiro ${ }^{1}$, Pedro R. da Silva ${ }^{2}\left(\mathbb{D}\right.$ and Jorge de Brito ${ }^{3, *}$ \\ 1 Instituto Superior Técnico, Universidade de Lisboa, 1649-004 Lisbon, Portugal; \\ tiagobarroqueiro87@gmail.com \\ 2 CERIS, Instituto Superior de Engenharia de Lisboa, Instituto Politécnico de Lisboa, \\ 1500-310 Lisbon, Portugal; silvapm@dec.isel.pt \\ 3 CERIS, Instituto Superior Técnico, Universidade de Lisboa, 1649-004 Lisbon, Portugal \\ * Correspondence: jb@civil.ist.utl.pt
}

Received: 17 October 2019; Accepted: 28 October 2019; Published: 30 October 2019

\begin{abstract}
The urgent need to change the less positive impacts of the construction industry on the environment, and more specifically the production and use of concrete, is the main motivation for the research for more efficient and environmentally sustainable solutions. This paper presented the results of an experimental campaign whose ultimate goal was to produce high-performance self-compacting concrete (SCC) using recycled aggregates (RA) from the precast industry. The results of the fresh-state and mechanical properties tests performed on six concrete mixes (using RA from the precast industry) were presented. The first concrete mix is a reference mix using natural aggregates only (100\% NA), and the remaining five mixes had various contents of fine (FRA) and coarse (CRA) recycled aggregates in concrete's composition: (2) 25/25\% (25\% RA); (3) 50/50\% (50\% RA); (4) $100 / 100 \%$ (100\% RA); (5) 0/100\% (100\% CRA); (6) 100/0\% (100\% FRA). The results showed that the high-performance concrete mixes with RA from the precast industry performed worse than the reference mix. However, taking into account all the mechanical properties studied, it can be concluded that RA from precast concrete elements are of very good quality and can be incorporated in the production of high-performance SCC. The potential demonstrated by the combined use of fine and coarse recycled aggregates was also emphasized. This type of work is expected to effectively contribute to raise awareness among the various players in the construction industry, particularly in the precast concrete industry, to the feasibility of using RA in significant quantities (notably coarse aggregates) and to the safety needed to assume structural functions, even for applications where high performance is required.
\end{abstract}

Keywords: high-performance self-compacting concrete; coarse and fine recycled aggregates from the precast industry; fresh properties; mechanical properties

\section{Introduction}

\subsection{Background}

The issue of self-compacting concrete (SCC) with recycled aggregates (RA) is of great relevance to the community, which increasingly demands that the construction industry adopts new processes that minimize negative impacts on the environment. SCC with RA is a technical solution that can achieve precisely those objectives. 
The use of RA in concrete production has a great environmental benefit through savings in natural aggregate (NA) extraction and the elimination of waste, resulting from the demolition of obsolete structures or, in the particular case of this study, from the waste from the precast industry.

The properties of RA are clearly influenced by the quality of the original concrete, especially the quality and quantity of mortar adhered to its surface. The quality of the mortar depends on the water/binder ratio used in the original concrete and its quality depends on the strength of the concrete and the crushing method used [1]. In this sense, RA from the precast industry usually have a higher quality compared to those obtained from construction and demolition waste (CDW). This is mainly due to the quality of the original precast concrete that usually has compressive strength values above 40-50 MPa and lower water-cement ratio, among others.

One of the main advantages of SCC is its ability to flow and compact only under the action of its own weight, filling the formwork with its reinforcement, tubes, negative, etc., to maintain the homogeneity [2]. Therefore, this type of concrete does not need to be vibrated (unlike conventional concrete), thus promoting a great environmental benefit, particularly in terms of energy saving and no noise during casting [3].

In conventional concrete, it is necessary to apply additional energy to vanquish the internal friction between the particles to allow them to mix and fill the molds correctly. However, in an SCC, this does not have to be done because the concrete itself achieves this effect. This is reflected in the fresh-state tests and is achieved by optimizing the mix composition and incorporating admixtures and superplasticizers.

The specific requirements for fresh SCC depend on the type of application, with particular emphasis on confinement conditions (concrete element geometry, quality, type, and location of reinforcement, among others), concrete laying equipment, concrete laying methods, and surface finishing methods [3].

The properties to be evaluated in the fresh-state test may be characterized by the following characteristics: Fluidity, flow velocity with or without obstructions, filling ability, flow ability, passing ability, and segregation resistance.

High-performance concrete (HPC) is currently used only in particular situations, such as in tall buildings and structures located in particularly harsh environments [4]. Given the need to flow in densely reinforced areas, it is sometimes necessary for this type of concrete to have self-compacting characteristics. This context justifies the need for high-performance self-compacting concrete (HPSCC). In fact, in situations where higher workability and better resistance to both mechanical loading and chemical attack may be required, HPSCC may be used [5]. The use of this type of concrete allows the structures to have a lifetime of 100 years or more [4].

The most relevant and enabling component of HPC production is silica fume. This allows improvements in mechanical properties, such as modulus of elasticity, flexural strength, and compressive strength, among others [6]. In addition, silica fume contributes to HPC's increased durability $[7,8]$. Silica fume has a greater impact on concrete compressive strength during the first 28 days. After 28 days, the concrete will gradually continue to gain strength, although the strength gaining rate is much slower [6]. The amount of silica fume to be used in HPC ranges from $10 \%$ to $15 \%$ in cement weight $[7,9]$. If a small amount of silica fume is incorporated (less than $5 \%$ ), its use will not be efficient [10]. On the other hand, for amounts greater than $15 \%$, the space between the cement particles will not be sufficient to accommodate all the silica, a part of which is thus wasted [11].

HPC consist of cement, water, fine and coarse aggregates, superplasticizer, and/or mineral additions (e.g., fly ash, blast furnace slag, and silica dust, among others) [12,13]. They usually use CEM I cement, class 42.5 or 52.5 , in large quantities of around $400-550 \mathrm{~kg} / \mathrm{m}^{3}$ with water-binder ratios between 0.25 and $0.35[10,14]$. This concrete has higher compressive strength than conventional concrete. Despite this, strength is not always the main property required. However, due to the high amounts of cement, HPC has higher environmental impacts than conventional concrete. Thus, in the context of sustainability in the construction industry, it is important to create a set of strategies regarding its use. Although there is no well-defined line of separation between conventional concrete 
and HPC, ACI 211.4R [15] characterizes HPC as concrete with a compressive strength greater than 41 MPa. NP EN 206-1 [2] considers that, to be classified as HPC, a concrete must have a strength class greater than $\mathrm{C} 50 / 60$.

The use of RA in the production of HPSCC is still incipient and very little work is available on the subject. Considering the particular use of RA from the precast industry, it was almost impossible to find scientifically based references. However, it was possible to find some published work on some of the main topics of this paper. For example, Farhad et al. [16] performed interesting work on developing HPSCC using RA and rubber granulate. The authors stated that the addition of RA did not significantly compromise its mechanical strength, thereby raising the produced mixes to a high-performance level.

Similarly, Grdic et al. [17] performed work on the properties of SCC prepared with coarse recycled aggregates (CRA) and noted minor losses in strength. On the other hand, Corinaldesi and Moriconi [18] studied the joint use of CRA and FRA in the production of SCC, concluding that while the use of fine recycled aggregates (FRA, used to replace sand) negatively affected compressive strength, the latter remained unchanged when CRA was used as a replacement of coarse natural aggregates (CNA). In the same sense, Santos et al. [19], who conducted a study on the mechanical performance evaluation of SCC with FRA and CRA from the precast industry, concluded that the RA used performed better than reported in similar works. They also concluded that 25\% RA, 50\% RA, and 100\% CRA mixes exhibited satisfactory mechanical and durability behavior for the production of concrete with structural functions.

\subsection{Objectives}

Because aggregates account for $55-80 \%$ of the concrete volume [5], this study focused on the use of RA from the precast industry replacing NA, which not only saves natural resources, but also frees landfill space. In addition, this study included substitute/complementary materials for cement the byproducts of silicon (silica fume) and coal burning for energy production (fly ash).

In this sense, six HPSCC mixes were produced with the following incorporation proportions (FRA/CRA \%): 0/0\%; 25/25\%; 50/50\%; 100/100\%, 0/100\%; 100/0\%.

To evaluate the fresh-state properties, the following tests were performed: The slump-flow test, V-funnel test, L-box test, $\mathrm{j}$-ring test, and the sieve segregation test.

To evaluate the mechanical properties, the following hardened state tests were performed: Density of hardened concrete, compressive strength, splitting tensile strength, secant elastic modulus of elasticity, ultrasonic pulse velocity test, abrasion resistance, creep and total shrinkage strain.

RA comes from crushing precast concrete parts with a compressive strength class of $65 \mathrm{MPa}$. RA were subjected to two crushing processes, a primary grinding followed by a secondary grinding, which is similar to what is done for NA.

The percentage of cement substitution with mineral additions $\left(f_{a d}\right)$, which included limestone filler (LF) and fly ash (FA), was kept constant in all the mixes. A $\mathrm{f}_{\text {ad }}$ value of $35 \%$ was considered, with $5 \%$ corresponding to LF and 30\% to FA. The amount of silica fume and cement was also kept constant in all mixes: $10 \%$ of silica fume and $450 \mathrm{~kg} / \mathrm{m}^{3}$ of cement. The $\mathrm{w} / \mathrm{c}$ ratio of all mixes produced was 0.44 .

In this paper, the results of the experimental campaign with HPSCC with RA were presented. In addition, HPSCC and RA were analyzed and discussed, and a comparison with similar studies was performed. In the analysis of these properties, the influence of RA's incorporation in SCC was evaluated. Also, the experimental results were compared with the models predicted in Eurocode 2 [20].

\section{Materials and Methods}

\subsection{Materials}

To carry out the experimental campaign, the following materials were selected:

- Type I cement (CEM I 52.5 R) produced according to NP EN 197-1 [21], with a density of $3200 \mathrm{~kg} / \mathrm{m}^{3}$, whose properties are shown in Tables 1 and 2; 
- Three mineral additions: Fly ash (FA), produced according to NP EN 450-1 [22] and NP EN 450-2 [23]; limestone filer (LF), produced according to LNEC-E466 [24]; and silica fume (SF), produced according to NP EN 13263-1 [25]. FA, LF, and SF a density corresponding to $2300 \mathrm{~kg} / \mathrm{m}^{3}$, $2720 \mathrm{~kg} / \mathrm{m}^{3}$, and $2010 \mathrm{~kg} / \mathrm{m}^{3}$, respectively, and their properties are shown in Tables 1 and 2;

- Two limestone coarse aggregates and two siliceous sands observing NP EN 12620 [26], namely: Gravel 1 (density $=2640 \mathrm{~kg} / \mathrm{m}^{3}$; water absorption $=1.60 \% ; D_{\max }=11 \mathrm{~mm}$ ), gravel 2 (density $=2690 \mathrm{~kg} / \mathrm{m}^{3}$; water absorption $\left.=0.80 \% ; D_{\max }=20 \mathrm{~mm}\right)$, coarse sand reference $0 / 4$ (density $=2670 \mathrm{~kg} / \mathrm{m}^{3}$; water absorption $\left.=0.40 \%\right)$, and fine sand reference $0 / 2\left(\right.$ density $=2670 \mathrm{~kg} / \mathrm{m}^{3}$; water absorption $=0.40 \%$ ). The particle size distribution is presented in Figure 1;

- RA from crushed concrete elements from precast industry of strength class $65 \mathrm{MPa}$ : One coarse recycled aggregate $(\mathrm{CRA})\left(\right.$ density $=2490 \mathrm{~kg} / \mathrm{m}^{3}$; water absorption $=2.20 \%$ ), and one fine recycled aggregate (FRA) (density $=2450 \mathrm{~kg} / \mathrm{m}^{3}$; water absorption $=7.5 \%$ ). Since the RA were used in substitution of NA, its particle size distribution is the same;

- A water-reducing admixture $\left(S_{p}\right)$, produced observing NP EN 934-1 [27] and NP EN 934-2 [28] (a superplasticizers in liquid form with a density $=1070 \mathrm{~kg} / \mathrm{m}^{3}$ );

- Tap water, which complied with NP EN 1008 [29].

Table 1. Chemical composition of the raw materials (\%).

\begin{tabular}{ccccc}
\hline Chemical Composition * & CEM I & FA & LF & SF \\
\hline $\mathrm{Al}_{2} \mathrm{O}_{3}$ & 5.24 & 24.7 & 0.13 & 0.54 \\
$\mathrm{CaCO}_{3}$ & - & - & 98.35 & - \\
$\mathrm{CaO}$ & 62.71 & 2.63 & - & 0.43 \\
$\mathrm{Cl}^{-}$ & 0.01 & $<0.01$ & - & - \\
$\mathrm{Fe}_{2} \mathrm{O}_{3}$ & 3.17 & 5.40 & 0.03 & 1.15 \\
$\mathrm{~K}_{2} \mathrm{O}$ & - & 1.11 & 0.02 & 0.86 \\
$\mathrm{MgO}$ & 2.23 & 1.01 & 0.40 & 0.43 \\
$\mathrm{Na}_{2} \mathrm{O}$ & - & 0.89 & - & 0.29 \\
$\mathrm{SiO}_{2}$ & 19.59 & 54.70 & 0.30 & 93.67 \\
$\mathrm{SO}_{3}$ & 3.13 & 1.38 & - & 0.25 \\
$\mathrm{TiO}_{2}$ & - & - & 0.01 & - \\
Insoluble residue & 1.37 & - & - & - \\
Loss of ignition & 2.94 & 5.10 & 43.80 & 2.54 \\
Surface area (BET) (m²/kg) & 325 & 430 & 456 & 15000 \\
(NP EN 196-6 [30]) & & & &
\end{tabular}

* The chemical composition of the raw materials was provided by the respective producers. CEM I: Cement type I 52.5 R; FA: Fly ash; LF: Limestone filer; SF: Silica fume.

Table 2. Grading of the raw materials.

\begin{tabular}{ccccc}
\hline \multirow{2}{*}{$\begin{array}{c}\text { Particle Size, } \\
\text { in Microns * }\end{array}$} & CEM I & FA & LF & SF \\
\cline { 2 - 5 } & 100 & 100 & 100 & 100 \\
1000 & 98 & 96 & 60 & 100 \\
100 & 38 & 45 & 20 & 80 \\
10 & 5 & 2 & 0 & 10 \\
1 & 0 & 0 & 0 & 2 \\
0.1 & 0 & 0 & \\
\hline
\end{tabular}

* The grading of the raw materials was provided by the respective producers. 


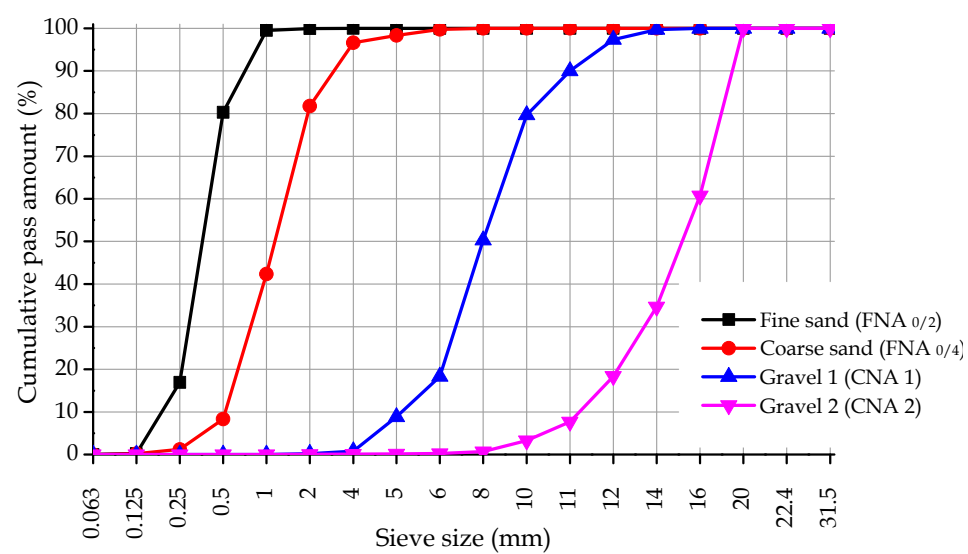

Figure 1. Particle size distribution of the natural aggregates [19].

\subsection{Mix Proportions}

SCC are made of coarse aggregates dispersed in a mortar matrix. Thus, once the properties of the mortar matrix suitable for obtaining SCC are defined, it becomes possible to separate the study of the mortars phase from the study of the concrete phase. A first justification for the separate analysis of mortars lies in the greater ease of execution compared to concrete. This facility results in the possibility of testing smaller volumes and faster mortar execution and testing.

Thus, the methodology followed in the present work was based on the method proposed by Nepomuceno [31,32], i.e., prior to the production of SCC, a previous study was performed on mortars to assess the parameters related to this phase (definition of water and superplasticizer volumes). After the mortar were designed, concrete was designed by defining the amount of coarse aggregate. Accordingly, the methodology recommended by Nepomuceno [31,32] was adopted, as has been done in numerous research papers [33-38].

Table 3 shows the mix proportions of all studied mixes.

Table 3. Mix proportions of the high-performance self-compacting concrete with recycled aggregates (HPSCCRA).

\begin{tabular}{|c|c|c|c|c|c|c|}
\hline $\begin{array}{l}\text { Mix Proportions } \\
\left(\mathrm{kg} / \mathrm{m}^{3}\right)\end{array}$ & $100 \%$ NA & $25 \%$ RA & $50 \%$ RA & $100 \%$ RA & $100 \%$ CRA & $100 \%$ FRA \\
\hline CEM I 52.5 R (C) & \multicolumn{6}{|c|}{437} \\
\hline Fly ash (FA) & \multicolumn{6}{|c|}{145} \\
\hline Limestone filler (LF) & \multicolumn{6}{|c|}{29} \\
\hline Silica fume (SF) & \multicolumn{6}{|c|}{27} \\
\hline Superplasticizer $\left(S_{p}\right)$ & \multicolumn{6}{|c|}{8} \\
\hline Water $(\mathrm{W})$ & \multicolumn{6}{|c|}{193} \\
\hline $\operatorname{Sand}_{0 / 2}\left(\mathrm{FNA}_{0 / 2}\right)$ & 162 & 122 & 81 & - & 162 & - \\
\hline Sand $_{0 / 4}\left(\mathrm{FNA}_{0 / 4}\right)$ & 484 & 363 & 242 & - & 484 & - \\
\hline FRA & - & 145 & 290 & 581 & - & 581 \\
\hline Gravel $_{1}\left(\mathrm{CNA}_{1}\right)$ & 389 & 292 & 195 & - & - & 389 \\
\hline Gravel $_{2}\left(\mathrm{CNA}_{2}\right)$ & 398 & 299 & 199 & - & - & 398 \\
\hline CRA & - & 184 & 369 & 737 & 737 & - \\
\hline $\mathrm{W} / \mathrm{C}$ ratio & \multicolumn{6}{|c|}{0.442} \\
\hline W/CM ratio & \multicolumn{6}{|c|}{0.317} \\
\hline $\mathrm{W} / \mathrm{FM}$ ratio & \multicolumn{6}{|c|}{0.303} \\
\hline
\end{tabular}

W/C, water/cement; W/CM, water/cementitious materials; W/FM, water/fine materials.

It was necessary to make some choices regarding the various mix parameters, namely:

- It was necessary to set a value for the ratio, in absolute volume, between the total amount of fine materials (cement and mineral admixtures) and of fine aggregates in the mix $\left(V_{p} / V_{s}\right)$, which 
should preferably be between 0.65 and 0.80 according to Nepomuceno [31,32]. $\mathrm{V}_{\mathrm{p}} / \mathrm{V}_{\mathrm{s}}=0.80$ was chosen using the elements available in the study of Silva and de Brito [35];

- $\quad$ Taking into account the desired strength, the percentage of cement substitution with mineral admixtures $\left(f_{a d}\right)$ was fixed. Thus, all the studied concrete mixes contemplated the incorporation of LF and FA (in substitution of cement). A $f_{\text {ad }}$ value of $35 \%$ was considered, with $5 \%$ corresponding to $\mathrm{LF}$ and $30 \%$ corresponding to FA;

- In all mixes, an absolute volume of cement $\mathrm{V}_{\mathrm{c}}=0.137 \mathrm{~m}^{3} / \mathrm{m}^{3}$ and a percentage of SF relative to the cement mass of $10 \%$ (corresponding to $V_{\mathrm{Sf}}=0.0137 \mathrm{~m}^{3} / \mathrm{m}^{3}$ ) were considered;

- $\quad \mathrm{V}_{\mathrm{w}} / \mathrm{V}_{\mathrm{p}}$ (ratio, in absolute volume, between the total amount of water and that of fine materials) and $\mathrm{S}_{\mathrm{p}} / \mathrm{p} \%$ (percentage, in mass, of superplasticizer and fine materials in the mix) were kept constant $\left(\mathrm{V}_{\mathrm{w}} / \mathrm{V}_{\mathrm{p}}=0.92\right.$ and $\left.\mathrm{S}_{\mathrm{p}} / \mathrm{p} \%=1.24\right)$;

- $\quad$ RA came from the crushing of precast elements with a $65 \mathrm{MPa}$ compressive strength class. RA were subjected to two crushing processes, a primary grinding followed by a secondary grinding, similar to what is done for NA.

\subsection{Test Methods}

\subsubsection{Fresh-State Tests}

Fresh-state tests were performed according to the parameters defined in NP EN 206-9 [39]. Namely, to assess the filling ability, the slump-flow test [40] and the V-funnel test [41] were used; for passing ability's evaluation, the L-box test [42] and the J-ring test [43] were used; and to assess resistance to segregation, the sieve segregation test was used [44].

\subsubsection{Hardened-State Tests}

The hardened concrete density test was performed according to NP EN 12390-7 [45] in 150-mm cubic edge specimens. For each reference and age, three specimens were molded and tested at 7, 28, and 91 days.

The compressive strength test was performed according to NP EN 12390-3 [46]. The test was carried out on 150-mm cubic edge specimens, as well as 150-mm-diameter and 300-mm-high cylindrical specimens. For each reference and age, three specimens were molded and tested at 7, 28, and 91 days.

The splitting tensile strength test was performed according to the methodology specified by NP EN 12390-6 [47]. The test was carried out on 150-mm-diameter and 300-mm-high cylindrical specimens. For each reference and age $(7,28,91$ days), three specimens were molded and tested.

The secant elastic modulus of elasticity test was performed according to the LNEC-E 397 [48]. The test was carried out on 150-mm-diameter and 300-mm-high cylindrical specimens. For each reference and age $(7,28,91$ days), three specimens were molded and tested.

The ultrasonic pulse velocity test was performed according to NP EN 12504-4 [49] by testing the same specimens used for compressive strength at the same ages $(7,28$, and 91 days).

Abrasion resistance was tested using a grinding wheel. Three specimens $(71 \mathrm{~mm} \times 71 \mathrm{~mm} \times 40 \mathrm{~mm})$ were tested according to DIN 52108 [50] at 91 days.

The total shrinkage strain was measured in two prismatic specimens $(100 \mathrm{~mm} \times 100 \mathrm{~mm} \times 500 \mathrm{~mm})$ for each concrete reference for 182 days (daily up to 14 days and weekly between 14 days and 182 days) according to LNEC specification E 398 [51].

Three prismatic specimens $(100 \mathrm{~mm} \times 100 \mathrm{~mm} \times 500 \mathrm{~mm})$ were mounted upright on creep frames at 28 days of age and a constant load was applied. Creep strain over time was evaluated every day for 91 days. The test was performed according to LNEC specification E 399 [52]. 


\section{Results and Discussion}

\subsection{Fresh-State Properties}

In this subchapter, the results obtained in the fresh HPSCC tests were analyzed.

\subsubsection{Slump-Flow Test}

The parameters evaluated were the time taken by the SCC to reach a circle of $500 \mathrm{~mm}$, called flow time $\left(t_{500}\right)$, and the slump-flow diameter (SF). Figures 2 and 3 show the results obtained for $t_{500}$ and $\mathrm{SF}$, respectively.

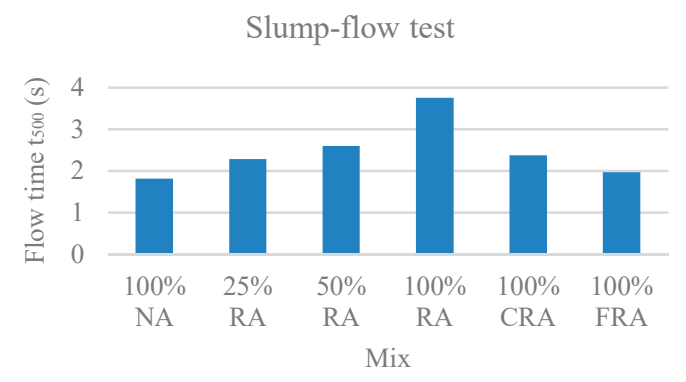

Figure 2. Flow time $\left(\mathrm{t}_{500}\right)$ test results.

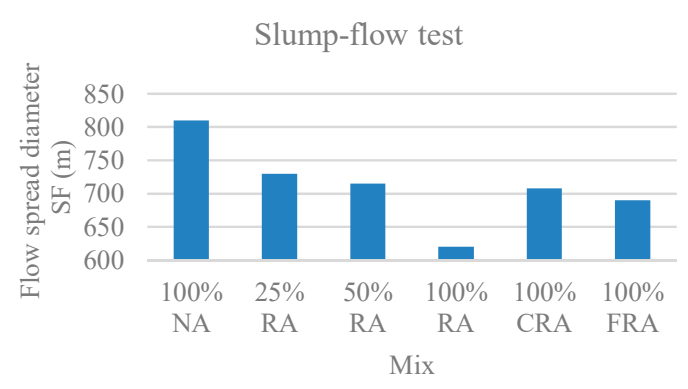

Figure 3. Slump-flow (SF) test results.

Through joint observation of Figures 2 and 3, in the mixes 100\% NA, 25\% RA, 50\% RA, and 100\% RA, there was an increase in flow time (Figure 2) and a decrease in flow spread diameter (Figure 3). This is justified by the higher absorption of RA compared to NA, given that, for higher RA substitution ratios, a larger amount of mixing water was probably absorbed by the aggregates. Grdic et al. [17] and Kebaili et al. [53] confirmed these trends.

In terms of both flow time $\left(t_{500}\right)$ and flow spread diameter, the results obtained by all mixes can be considered satisfactory. In general, there was a good coarse aggregate distribution without any exudation or segregation phenomenon. Coarse aggregates were visible even at the flow spread limit.

According to the classification given by NP EN 206-9 [39], all mixes fell into class VS2 (VS $\geq 2$ s) except $100 \%$ NA, which had the shortest flow time, belonging to class VS1 (VS $\leq 2 \mathrm{~s}$ ).

As for the flow spread diameter, the 25\% RA, 50\% RA, 100\% CRA, and 100\% FRA mixes fell into the slump-flow class SF2 (660 mm $\leq$ SF $\leq 750 \mathrm{~mm})$. The 100\% NA mix had the largest flow spread diameter, belonging to slump-flow class SF3 (760 mm $\leq \mathrm{SF} \leq 850 \mathrm{~mm}$ ). On the other hand, 100\% RA had the smallest flow spread diameter, belonging to slump-flow class SF1 (550 mm $\leq \mathrm{SF} \leq 650 \mathrm{~mm}$ ).

\subsubsection{V-Tunnel Test}

The time that the sample takes to fully flow through the V-funnel $\left(\mathrm{T}_{\mathrm{V}}\right)$ was the parameter evaluated in this test. The results are presented in Figure 4. 


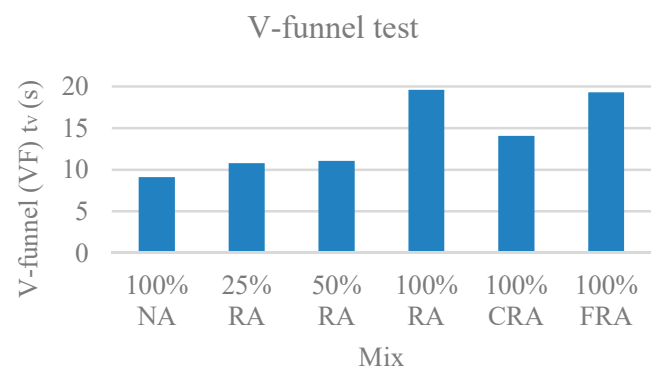

Figure 4. V-funnel $\left(\mathrm{T}_{\mathrm{V}}\right)$ test results.

It was found that the flow time through the V-funnel increased with the percentage of RA. This trend is justified by RA's higher water absorption and its rougher surface compared to that of NA [54].

For all mixes, the values obtained in the flow time through the V-funnel fit those referred in NP EN 206-9 [39], ranging generally between $9 \mathrm{~s}$ and $20 \mathrm{~s}$. Excluding the 100\% NA mix, all mixes fell into class VF2 ( $9 \mathrm{~s} \leq \mathrm{VF} \leq 25 \mathrm{~s})$. The mix with $100 \%$ NA had the shortest flow time, and the only mix belonging to class VF1 (VF $<9 \mathrm{~s})$.

Visual observation allowed for the checking of the non-blockage effect of coarse aggregate in the V-funnel narrow passage. No exudation was observed. After the test, concrete continued to appear as a uniformly distributed mass.

\subsubsection{L-Box Test}

In this test, the passing ability index in the L-box (PL) was evaluated. Figure 5 presents the results obtained.

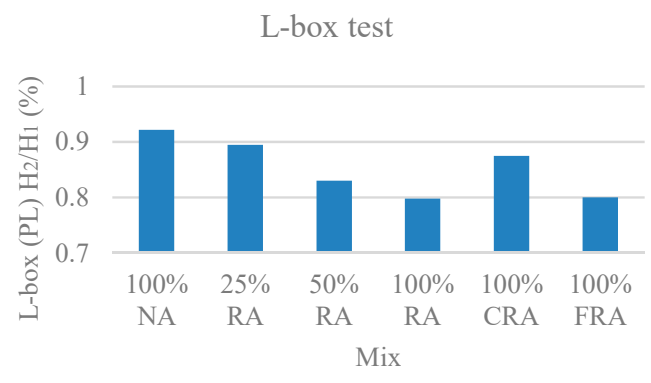

Figure 5. L-box test results.

It was found that the passing ability index decreased with the incorporation of RA. This was due to the higher water absorption of CRA compared to NA. This trend was also found by Kebaili et al. [53].

The average values obtained are close, and no exudation or segregation was observed. For this test, the NP EN 206-9 [39] reference value for $\mathrm{H}_{2} / \mathrm{H}_{1}$ was greater than $80 \%$. Therefore, the results obtained fell within this limit, ranging from $80 \%$ to $92 \%$. Therefore, all mixes belonged to class PL2.

\subsubsection{Sieve Segregation Test}

In this test, the segregated portion (SR) was evaluated, which corresponds to the proportion of the sample passing through the sieve, relative to the total amount. The results are presented in Figure 6.

The segregation index tended to decrease with the incorporation of RA. This was due to the higher water absorption of RA compared to NA. A similar trend was found in the study of Grdic et al. [17].

These results were within the values referred in NP EN 206-9 [39], i.e., always below $20 \%$.

The mixes with $100 \%$ RA and $100 \%$ FRA fell into the SR2 class (SR $\leq 15 \%$ ), corresponding to a smaller tendency toward segregation. The remaining mixes fell into class SR1 (SR $\leq 20 \%)$. 


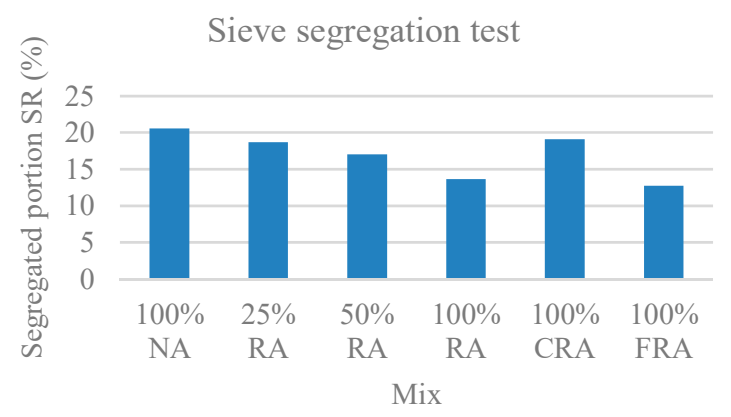

Figure 6. Sieve segregation test results.

\subsubsection{J-Ring Test}

In this test, the time it takes SCC to reach a $500-\mathrm{mm}$ circle $\left(\mathrm{T}_{500}\right)$, the J-ring slump flow diameter $\left(\mathrm{SF}_{\mathrm{J}}\right)$, and the ring passing ability $(\mathrm{PJ})$, which corresponds to the blocking gap, were evaluated. Figure 7 , Figure 8, and Figure 9 show the results obtained for $\mathrm{T}_{500}, \mathrm{SF}_{\mathrm{J}}$, and PJ, respectively.

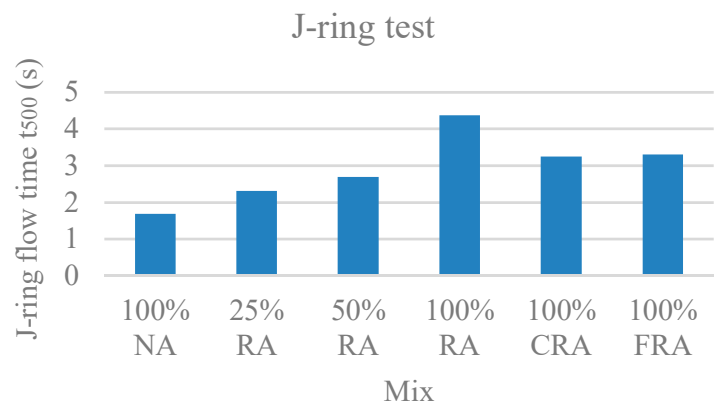

Figure 7. J-ring flow time $\left(t_{500}\right)$ test results.

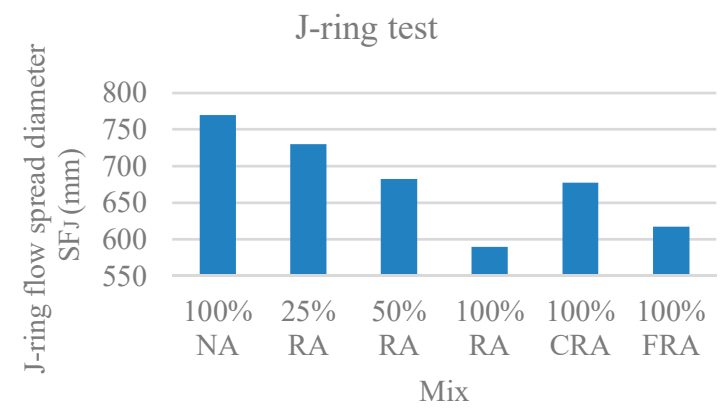

Figure 8. J-ring flow spread diameter test results.

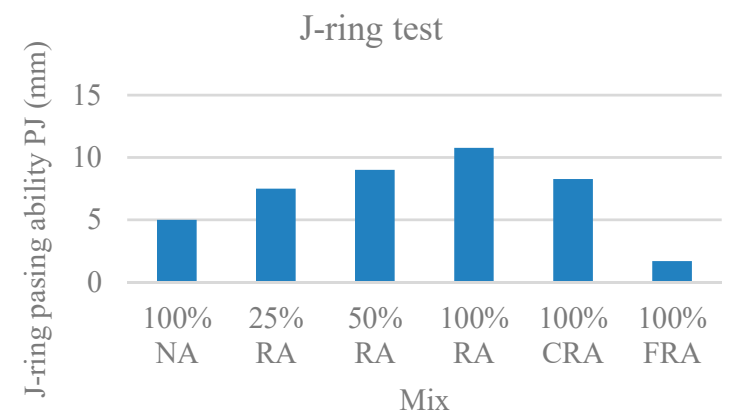

Figure 9. J-ring passing ability PJ test results.

Observing the results, with the incorporation of RA, the flow time increased (Figure 7), the J-ring flow spread decreased (Figure 8), and the passing ability increased (Figure 9). The results of the 
J-ring spread diameter $\left(\mathrm{SF}_{\mathrm{J}}\right)$ and the slump-flow diameter $(\mathrm{SF})$ results were strongly correlated (ratio of 0.88), with a linear relationship (Figure 10). This means that both the slump-flows (SF $F_{J}$ and SF) vary similarly with the RA content, i.e., the fluidity and passing ability were directly interconnected. Safiuddin et al. [55] found a similar trend, obtaining a 0.99 correlation coefficient.

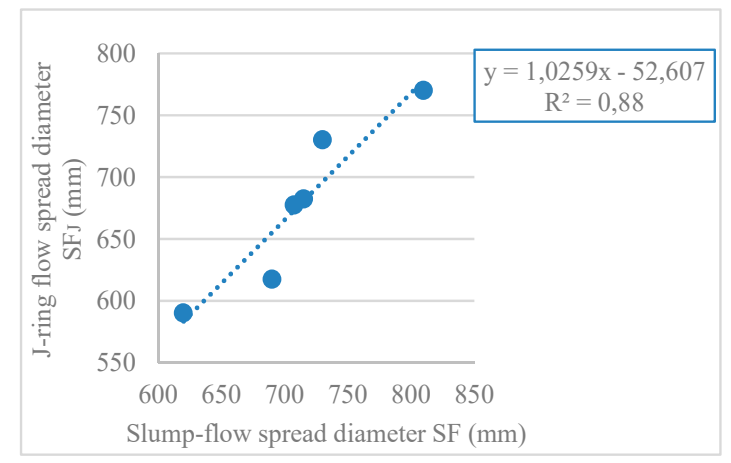

Figure 10. J-ring flow spread diameter $\mathrm{SF}_{\mathrm{J}}$ and slump-flow spread diameter $\mathrm{SF}$ correlation.

According to NP EN 206-9's [39] classification, the 100\% NA, 25\% RA, and 50\% RA mixes belonged to spreading class VJ1 (VJ <3). The remaining mixes belonged to spreading class VJ2 (VJ $\geq 3$ ).

Regarding the spreading diameter, the 100\% NA and 25\% RA mixes belonged to spreading class $\mathrm{SF}_{\mathrm{J}} 3$. The $50 \% \mathrm{RA}, 100 \% \mathrm{CRA}$, and $100 \%$ FRA mixes belonged to the $\mathrm{SF}_{\mathrm{J}} 2$ class. Only the $100 \% \mathrm{RA}$ mix belonged to $\mathrm{SF}_{\mathrm{J}} 1$ class.

The j-ring passing ability values (PJ) were generally found in class PJ2 for all studied mixes, with values below $10 \mathrm{~mm}$, which correspond to good flowability.

\subsection{Hardened State Properties}

In this subchapter, the results obtained in the hardened SCC were analyzed, namely: Density, compressive strength, splitting tensile strength, modulus of elasticity, ultrasonic pulse velocity, abrasion resistance, shrinkage, and creep.

\subsubsection{Density}

Table 4 and Figure 11 show the results obtained in the density test.

Table 4. Density at 7, 28, and 91 days.

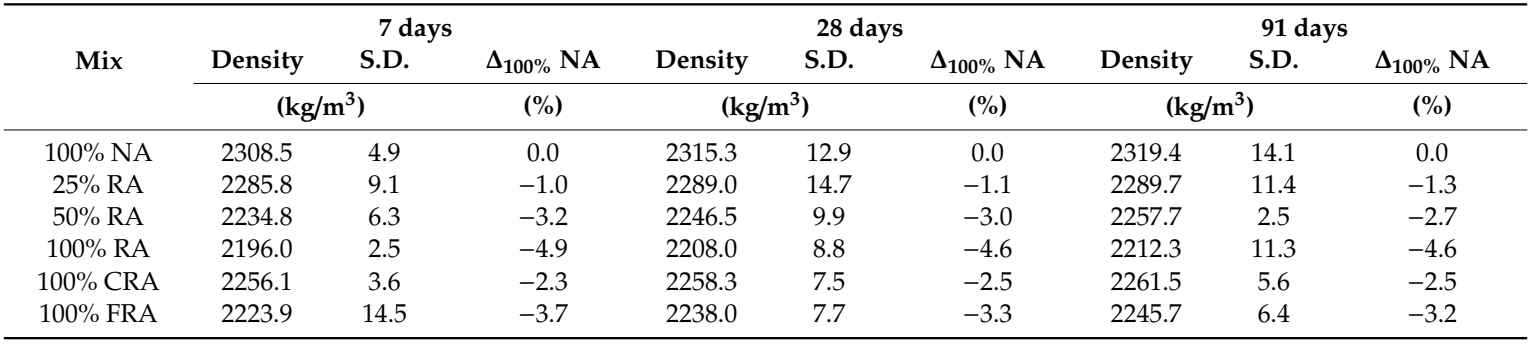

It was found that the density slightly increased with age (average increase of $8 \%$ from 28 days to 91 days). This is justified by the longer curing period, which incorporated more water into the sample, increasing its mass.

Analyzing the relative position of the mixes shown in Figure 11, it appears that density decreased with the incorporation of RA, given the lower density of RA compared to NA's. The highest density loss was found in the 100\% RA mix (5\% loss from the reference SCC). A similar trend was found in the work of Pereira-de-Oliveira et al. [54], where the authors obtained a 3\% density loss (100\% RA concrete) compared to the reference SCC. 


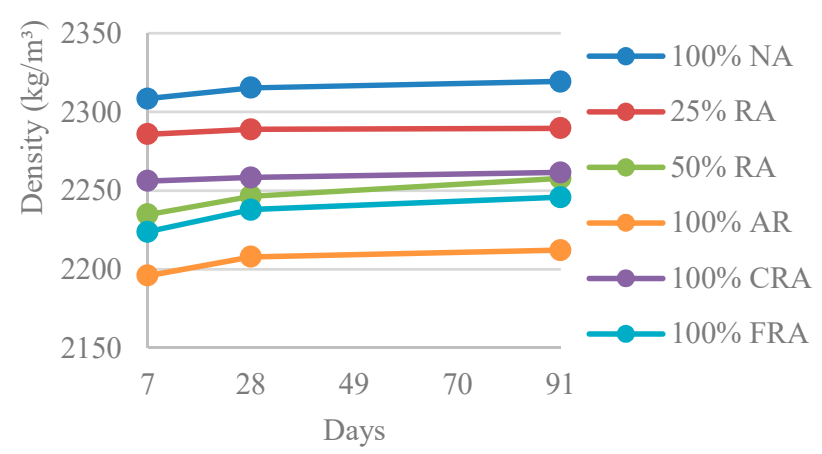

Figure 11. Density at 7, 28, and 91 days.

\subsubsection{Compressive Strength $(15 \mathrm{~cm} \times 15 \mathrm{~cm} \times 15 \mathrm{~cm}$ Cubes $)$}

Table 5 and Figure 12 show the results of compressive strength in cubes with $15 \mathrm{~cm} \times 15 \mathrm{~cm} \times$ $15 \mathrm{~cm}\left(f_{c m, c}\right)$.

Table 5. Compressive strength $(15 \mathrm{~cm} \times 15 \mathrm{~cm} \times 15 \mathrm{~cm}$ cubes $)$ at 7, 28, and 91 days.

\begin{tabular}{|c|c|c|c|c|c|c|c|c|c|c|c|c|}
\hline \multirow{3}{*}{ Mix } & \multicolumn{4}{|c|}{7 days } & \multicolumn{4}{|c|}{28 days } & \multicolumn{4}{|c|}{91 days } \\
\hline & $f_{c m, c, 7 d}$ & S.D. & C.V. & $\Delta_{100} \%$ NA & $f_{c m, c, 28 d}$ & S.D. & C.V. & $\Delta_{100} \%$ NA & $f_{c m, c, 91 d}$ & S.D. & C.V. & $\Delta_{100} \%$ NA \\
\hline & \multicolumn{2}{|c|}{ (MPa) } & $(\%)$ & $(\%)$ & \multicolumn{2}{|c|}{ (MPa) } & $(\%)$ & $(\%)$ & \multicolumn{2}{|c|}{ (MPa) } & $(\%)$ & $(\%)$ \\
\hline $100 \%$ NA & 78.4 & 0.3 & 0.4 & 0.0 & 81.9 & 2.5 & 3.1 & 0.0 & 87.5 & 0.5 & 0.6 & 0.0 \\
\hline $25 \%$ RA & 76.8 & 2.8 & 3.6 & -2.0 & 80.7 & 0.4 & 0.5 & -1.4 & 86.7 & 1.3 & 1.5 & -0.9 \\
\hline $50 \%$ RA & 74.5 & 0.6 & 0.8 & -5.0 & 79.5 & 2.5 & 3.1 & -2.9 & 84.3 & 2.1 & 2.5 & -3.7 \\
\hline $100 \%$ RA & 70.8 & 1.4 & 2.0 & -9.7 & 75.0 & 0.5 & 0.7 & -8.4 & 79.9 & 1.9 & 2.4 & -8.7 \\
\hline $100 \%$ CRA & 75.9 & 1.2 & 1.6 & -3.1 & 80.3 & 5.9 & 7.3 & -1.9 & 84.7 & 1.0 & 1.2 & -3.2 \\
\hline $100 \%$ FRA & 72.6 & 0.2 & 0.3 & -7.4 & 78.0 & 2.2 & 2.8 & -4.8 & 83.6 & 3.1 & 3.7 & -4.5 \\
\hline
\end{tabular}

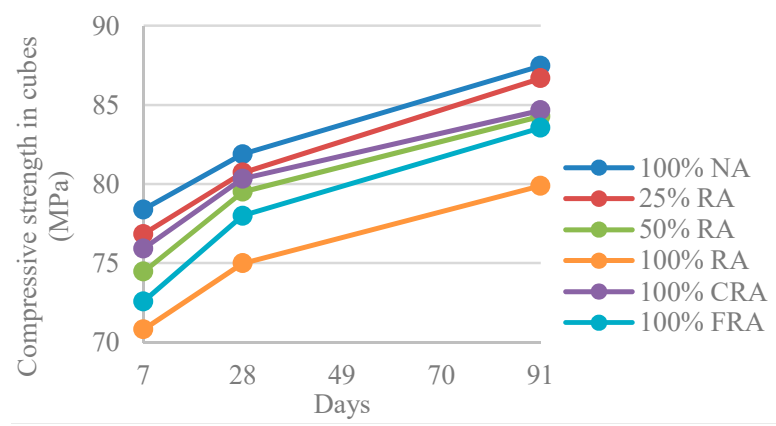

Figure 12. Compressive strength $(15 \mathrm{~cm} \times 15 \mathrm{~cm} \times 15 \mathrm{~cm}$ cubes $)$ at 7,28 , and 91 days.

All mixes developed strength rapidly up to 7 days, reaching, on average, about $89 \%$ of the strength at 91 days. This is justified by the presence of LF [17] and of SF [6].

Figure 12 shows that replacing NA with RA caused compressive strength decreases from the reference SCC (100\% NA) by $1-9 \%$. The compressive strength differences were similar at 7,28 , and 91 days. This is explained by the poorer quality of RA due to their adhered mortar that is responsible for increased aggregates' porosity and cracking, weakening the transition zone connections between RA and the new binder [56].

The same trends have been found by several authors [17,54,57,58]. Grdic et al. [17] and Pereira-de-Oliveira et al. [54] obtained a compressive strength reduction of $8 \%$ and $5 \%$, respectively, comparing the SCC with NA only and the SCC with 100\% RA (at 28 days).

Analyzing the failure surfaces in the cubic specimens due to uniaxial compression, they showed satisfactory failures (Figures 13-15) according to NP EN 12390-3 [36]. The type of failure obtained (explosive failure) is normal in HPSCC, according to Parande [7]. 


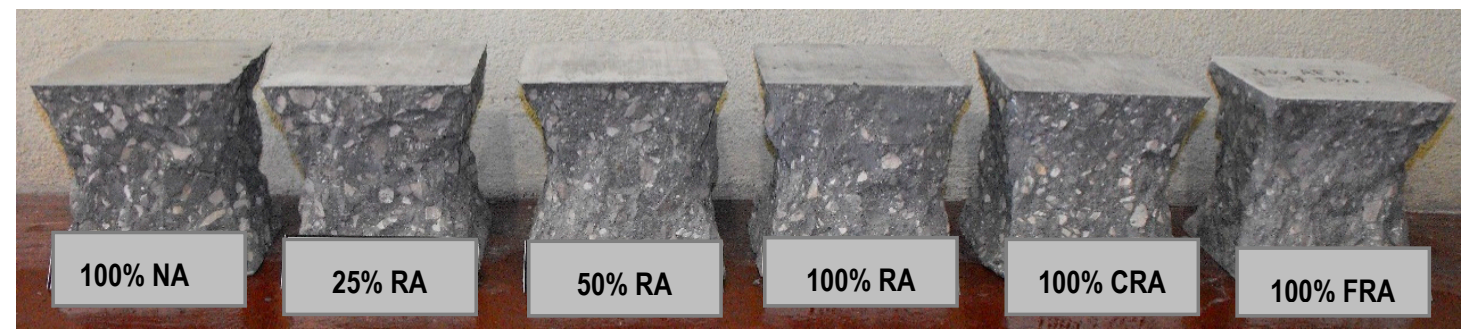

Figure 13. Failure surfaces presented by the different concrete mixes at seven days.

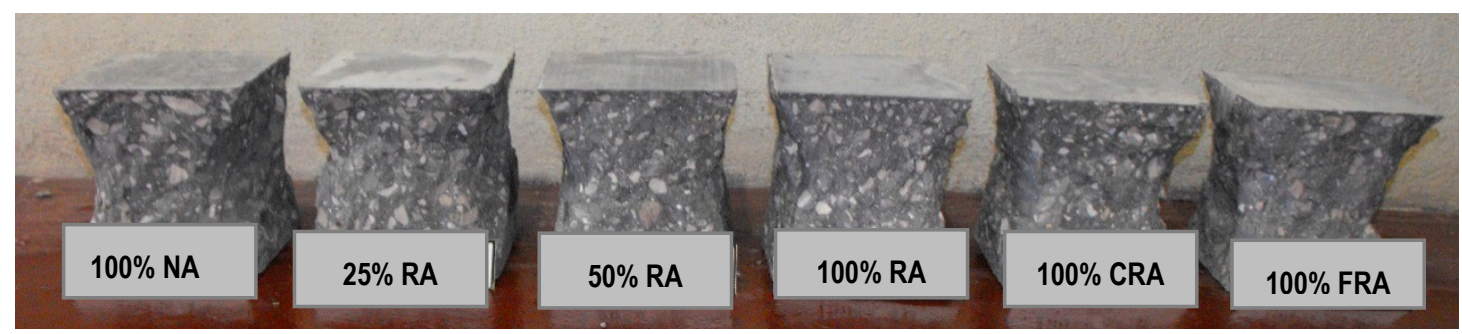

Figure 14. Failure surfaces presented by the different concrete mixes at 28 days.

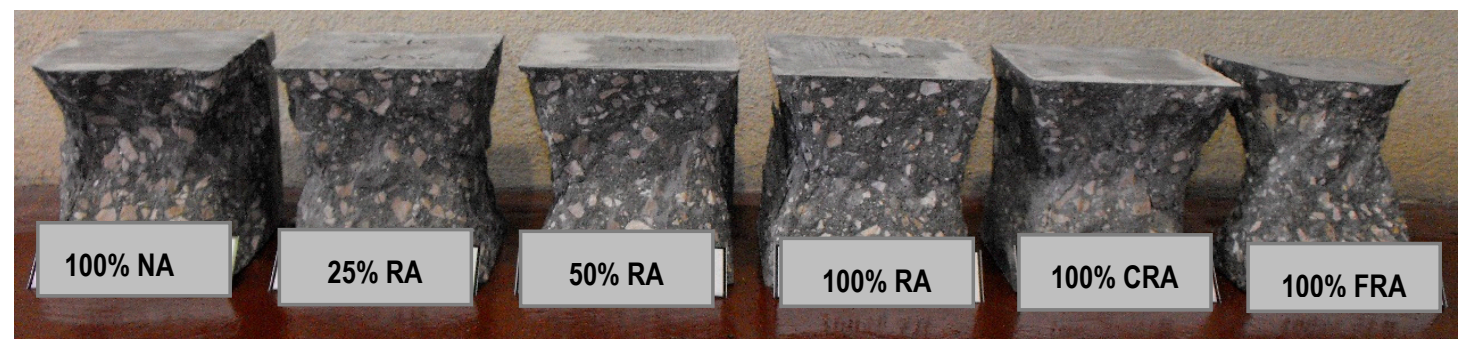

Figure 15. Failure surfaces presented by the different concrete mixes at 91 days.

The compressive strength results showed that the reference mix (100\% NA) with no RA presented higher compressive strength, reaching $82 \mathrm{MPa}$ and $87 \mathrm{MPa}$ at 28 and 91 days, respectively. The $100 \%$ RA mix had the lowest compressive strength of $75 \mathrm{MPa}$ and $80 \mathrm{MPa}$ at 28 and 91 days, respectively ( $8 \%$ reduction when compared to the reference mix).

Thus, according to the results at 28 days, the criteria defining HPC were met (according to ACI 211 [15], which defines HPC as having compressive strength greater than $41 \mathrm{MPa}$ ).

From Figure 16, a close correlation was found between the compressive strength and density (linear correlation with $\mathrm{R}^{2}=0.96, \mathrm{R}^{2}=0.85$ and $\mathrm{R}^{2}=0.94$ ).

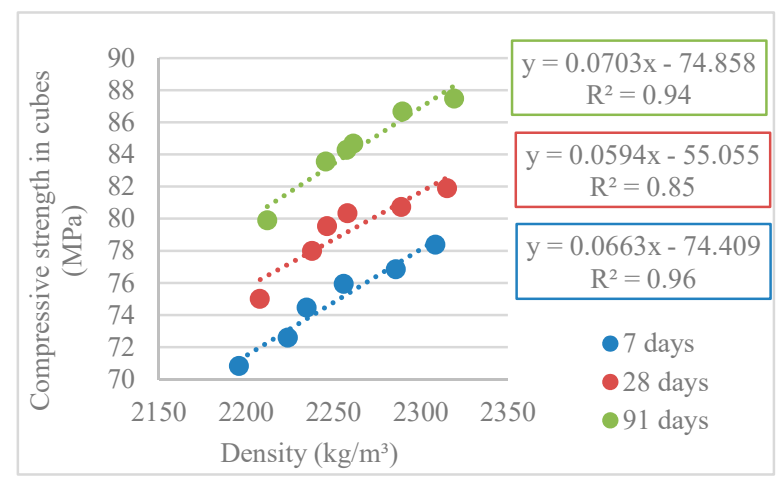

Figure 16. Correlation between compressive strength in cubes $(15 \mathrm{~cm} \times 15 \mathrm{~cm} \times 15 \mathrm{~cm})$ and density at 7,28 , and 91 days. 


\subsubsection{Compressive Strength $(\phi 15 \mathrm{~cm} \times 30$-cm Cylinders $)$}

Table 6 and Figure 17 show the results of compressive strength in $\phi 15 \mathrm{~cm} \times 30 \mathrm{~cm}$ cylinders $\left(f_{c m, c y l}\right)$.

Table 6. Compressive strength $(\phi 15 \mathrm{~cm} \times 30-\mathrm{cm}$ cylinders $)$ at 28 and 91 days.

\begin{tabular}{|c|c|c|c|c|c|c|}
\hline \multirow{3}{*}{ Mix. } & \multicolumn{3}{|c|}{28 days } & \multicolumn{3}{|c|}{91 days } \\
\hline & $f_{c m, c y l, 28 d}$ & S.D. & $\Delta_{100 \%}$ NA & $f_{c m, c y l, 91 d}$ & S.D. & $\Delta_{100 \%}$ NA \\
\hline & \multicolumn{2}{|c|}{ (MPa) } & $(\%)$ & \multicolumn{2}{|c|}{ (MPa) } & $(\%)$ \\
\hline $100 \%$ NA & 78.9 & 1.1 & 0.0 & 85.9 & 1.4 & 0.0 \\
\hline $25 \%$ RA & 75.2 & 1.1 & -4.7 & 82.3 & 2.8 & -4.2 \\
\hline $50 \%$ RA & 69.9 & 2.0 & -11.4 & 79.3 & 3.0 & -7.7 \\
\hline $100 \%$ RA & 61.0 & 1.8 & -22.6 & 65.8 & 1.0 & -23.4 \\
\hline $100 \%$ CRA & 71.1 & 2.1 & -9.9 & 80.7 & 1.1 & -6.1 \\
\hline $100 \%$ FRA & 65.9 & 1.2 & -16.5 & 73.3 & 1.3 & -14.7 \\
\hline
\end{tabular}

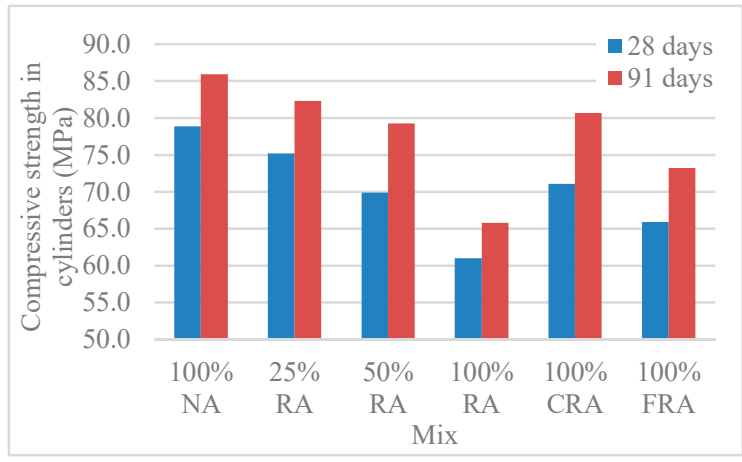

Figure 17. Compressive strength $(\phi 15 \mathrm{~cm} \times 30-\mathrm{cm}$ cylinders $)$ at 28 and 91 days.

The analysis of Table 6 and Figure 17 showed a reduction of compressive strength with the replacement of NA with RA (such as in cubes' compressive strength, and for the same reason). The variations were between $4 \%$ and $23 \%$ and, as expected, the compressive strength increased with age.

Analysis of the failure surfaces obtained in cylindrical specimens revealed satisfactory failures (Figure 18) due to uniaxial compression, according to NP EN 12390-3 [46]. The type of failure obtained was explosive (as in cubic specimens). According to Parande [7], this type of failure is normal in HPC.

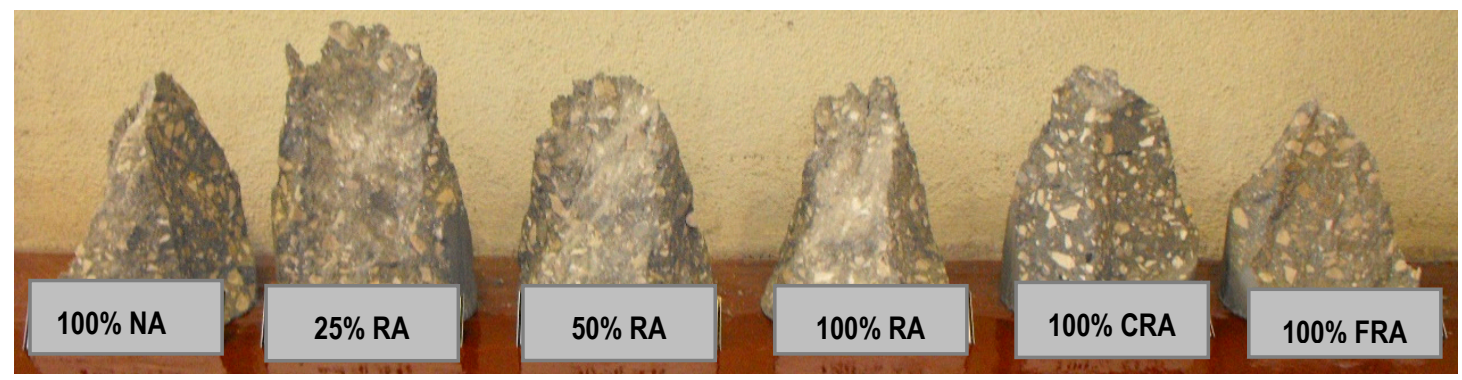

Figure 18. Failure surfaces presented by the different concrete mixes at 28 days.

Table 7 and Figure 19 show the compressive strength overall correlation among cubic and cylindrical specimens. 
Table 7. Compressive strength correlation among cubic/cylindrical specimens (28 and 91 days).

\begin{tabular}{|c|c|c|c|c|c|c|}
\hline \multirow{3}{*}{ Mix. } & \multicolumn{3}{|c|}{28 days } & \multicolumn{3}{|c|}{91 days } \\
\hline & $f_{c m, c, 28 d}$ & $f_{c m, c y l, 28 d}$ & \multirow{2}{*}{$f_{c m, c y l, 28 d} / f_{c m, c, 28 d}$} & $f_{c m, c, 91 d}$ & $f_{c m, c y l, 91 d}$ & \multirow{2}{*}{$f_{c m, c y l, 91 d} / f_{c m, c, 910}$} \\
\hline & \multicolumn{2}{|c|}{ (MPa) } & & \multicolumn{2}{|c|}{ (MPa) } & \\
\hline $100 \%$ NA & 81.9 & 78.9 & 0.96 & 87.5 & 85.9 & 0.98 \\
\hline $25 \%$ RA & 80.7 & 75.2 & 0.93 & 86.7 & 82.3 & 0.95 \\
\hline $50 \%$ RA & 79.5 & 69.9 & 0.88 & 84.3 & 79.3 & 0.94 \\
\hline $100 \%$ RA & 75.0 & 61.0 & 0.81 & 79.9 & 65.8 & 0.82 \\
\hline $100 \%$ CRA & 80.3 & 71.1 & 0.89 & 84.7 & 80.7 & 0.95 \\
\hline $100 \%$ FRA & 78.0 & 65.9 & 0.84 & 83.6 & 73.3 & 0.88 \\
\hline
\end{tabular}

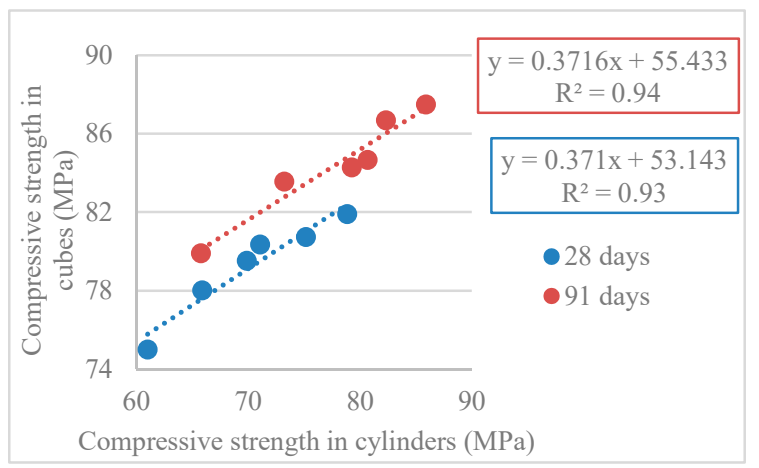

Figure 19. Compressive strength correlation among cubic/cylindrical specimens (28 and 91 days).

At 28 and 91 days, the compressive strength in cylinders was, on average, 0.89 and 0.92 of that in cubes at 28 and 91 days, respectively (Table 7). In other words, the conversion factor of cubic specimens relative to cylindrical specimens was approximately 0.89 and 0.92 at 28 and 91 days. This factor is close to the values given in Table 7 of NP EN 206-1 [2], which range from 0.80 (class C8/10) to 0.87 (class C100/ 115) at 28 days.

Table 8 shows the characteristic strength values for cubes and cylinders specimens. The characteristic strength values $\left(f_{c k}\right)$ were obtained from Equation (1), present in Table 3.1 from Eurocode 2 [20]:

$$
f_{c k}=f_{c m}-8
$$

Table 8. NP EN 206-1 [2] compressive strength classes.

\begin{tabular}{|c|c|c|c|c|c|c|c|}
\hline \multirow{3}{*}{ Mix. } & \multicolumn{4}{|c|}{ Experimental Values } & \multicolumn{3}{|c|}{ NP EN 206-1 Values } \\
\hline & $f_{c m, c y l, 28 d}$ & $f_{c m, c, 28 d}$ & $f_{c k, c y l}$ & $f_{c k, c}$ & \multirow{2}{*}{ Class } & $f_{c k, c y l}$ & $f_{c k, c}$ \\
\hline & \multicolumn{4}{|c|}{ (MPa) } & & \multicolumn{2}{|c|}{ (MPa) } \\
\hline $100 \%$ NA & 78.9 & 81.9 & 70.9 & 73.9 & $\mathrm{C} 55 / 67$ & 55 & 67 \\
\hline $25 \%$ RA & 75.2 & 80.7 & 67.2 & 72.7 & C55/67 & 55 & 67 \\
\hline $50 \%$ RA & 69.9 & 79.5 & 61.9 & 71.5 & C55/67 & 55 & 67 \\
\hline $100 \%$ RA & 61.0 & 75.0 & 53.0 & 67.0 & $\mathrm{C} 50 / 60$ & 50 & 60 \\
\hline $100 \%$ CRA & 71.1 & 80.3 & 63.1 & 72.3 & C55/67 & 55 & 67 \\
\hline $100 \%$ FRA & 65.9 & 78.0 & 57.9 & 70.0 & C55/67 & 55 & 67 \\
\hline
\end{tabular}

Thus, a class was assigned according to the quality and safety control criteria specified in NP EN 206-1 [2]. As seen in Table 8, only the 100\% RA mix belonged to strength class C50/60, while the rest of the mixes belonged to the class above, C55/67. According to NP EN 206-1 [2], all mixes were classified as HPC. The NP EN 206-1 standard considers that a mix classified as HPC must be of a strength class greater than $\mathrm{C} 50 / 60$. 


\subsubsection{Splitting Tensile Strength}

Table 9 and Figure 20 show the results of the splitting tensile strength test on cylinders with $\$ 15 \mathrm{~cm} \times 30 \mathrm{~cm}\left(f_{\mathrm{ctm}, \mathrm{sp}}\right)$. Figure 20 shows that the substitution of NA with RA was responsible for a decrease in splitting tensile strength. The lowest strength, $3.78 \mathrm{MPa}$ and $4.33 \mathrm{MPa}$ at 28 and 91 days, respectively, corresponded to the mix with $100 \%$ RA. The loss of strength in mixes with RA ranged from $7 \%$ to $32 \%$. This is explained by the adhered mortar in RA [57]. Comparing SCC with 100\% NA and SCC with 100\% RA (at 28 days), Kou and Poon [59] and Modani and Mohitkar [58] achieved strength losses of $36 \%$ and $37 \%$, respectively.

Table 9. Splitting tensile strength (28 and 91 days).

\begin{tabular}{|c|c|c|c|c|c|c|c|c|}
\hline \multirow{3}{*}{ Mix. } & \multicolumn{4}{|c|}{28 days } & \multicolumn{4}{|c|}{91 days } \\
\hline & $f_{c t m, s p, 28 d}$ & S.D. & C.V. & $\Delta_{100 \%}$ NA & $f_{c t m, s p, 91 d}$ & S.D. & C.V. & $\Delta_{100 \%}$ NA \\
\hline & \multicolumn{2}{|c|}{ (MPa) } & $(\%)$ & $(\%)$ & \multicolumn{2}{|c|}{ (MPa) } & $(\%)$ & $(\%)$ \\
\hline $100 \%$ NA & 5.6 & 0.5 & 8.9 & 0.0 & 6.2 & 0.1 & 1.6 & 0.0 \\
\hline $25 \%$ RA & 5.0 & 0.4 & 8.0 & -10.1 & 5.8 & 0.3 & 5.2 & -6.7 \\
\hline $50 \%$ RA & 4.3 & 0.5 & 11.6 & -23.4 & 5.3 & 0.4 & 7.5 & -15.1 \\
\hline $100 \%$ RA & 3.8 & 0.7 & 18.4 & -32.0 & 4.3 & 0.1 & 2.3 & -30.5 \\
\hline $\begin{array}{l}100 \% \\
\text { CRA }\end{array}$ & 4.5 & 0.1 & 2.2 & -19.2 & 5.5 & 0.1 & 1.8 & -11.0 \\
\hline $\begin{array}{l}100 \% \\
\text { FRA }\end{array}$ & 4.0 & 0.4 & 10.0 & -28.4 & 5.0 & 0.4 & 8.0 & -20.2 \\
\hline
\end{tabular}

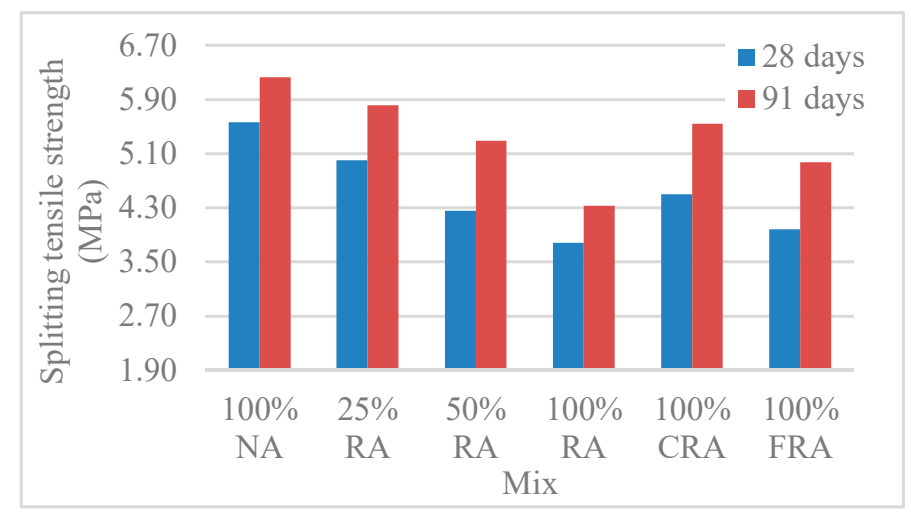

Figure 20. Splitting tensile strength (28 and 91 days).

Figure 20 shows that the splitting tensile strength increased with age (as predicted). At 28 days, concrete achieved, on average, $78 \%$ of the strength at 91 days. Panda and Bal [57] obtained similar results, i.e., at 28 days, the splitting tensile strength reached $85 \%$ of the strength at 91 days.

This test made it possible to observe the failure surface of the test specimens. Thus, Figures 21 and 22 show the typical failure surfaces (at 28 and 91 days). A uniform distribution of the coarse aggregate in the mixes was observed throughout the specimens, without particle agglomeration or any segregation or exudation. Along the failure surface, small air bubbles were observed, but they were not interconnected. These bubbles corresponded to the air trapped in HPSCC, as it did not undergo a vibration process.

Eurocode 2 [20] presents an equation that relates splitting tensile strength with compressive strength obtained in cylinders. Thus, for the calculation of splitting tensile strength $\left(f_{c t m, s p}\right)$ from the experimental values of cylinders compressive strength $\left(f_{c m, c y l}\right)$, Equation (2) from Table 3.1 of Eurocode $2[20]$ was used:

$$
f_{c t m, s p}=2.12 \ln \left[1+\left(\frac{f_{c m, c y l}}{10}\right)\right] / 0.9(>\mathrm{C} 50 / 60)
$$




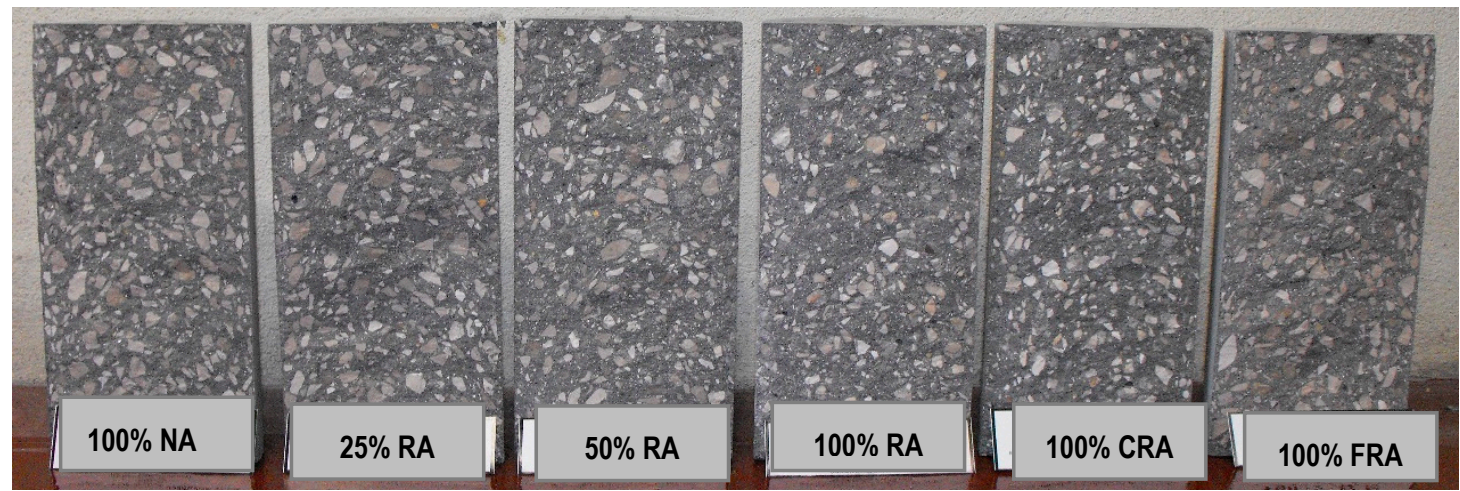

Figure 21. Failure surfaces for all mixes at 28 days.

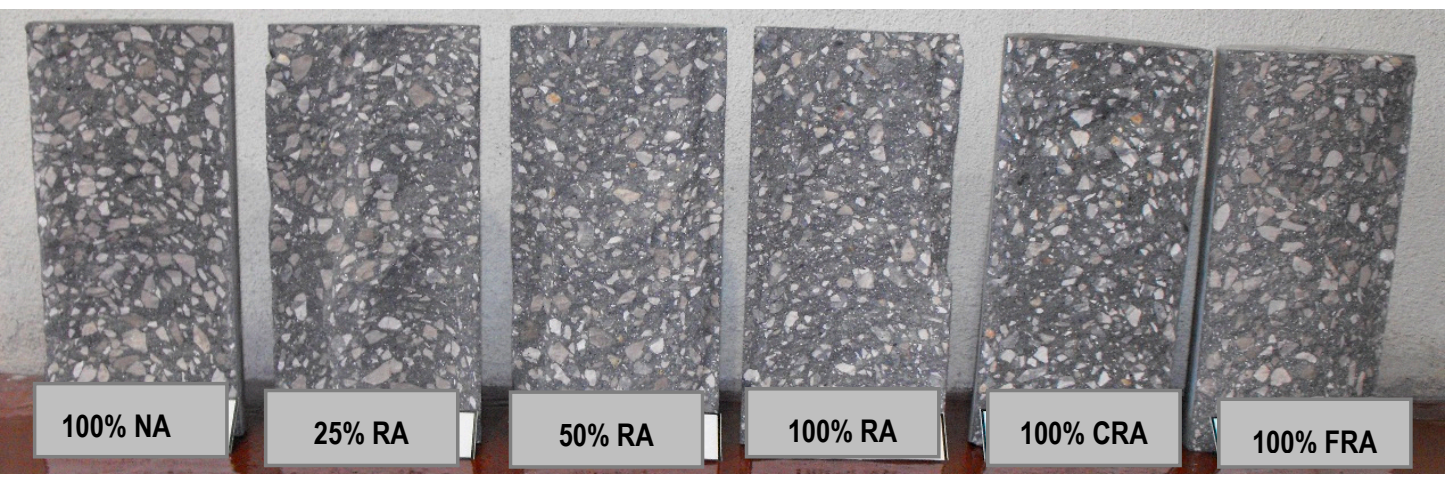

Figure 22. Failure surface for all mixes at 91 days.

In this equation, the axial tensile strength was considered to correspond to $90 \%$ of the splitting tensile strength, as suggested in Eurocode 2 [20].

Table 10 compares the tensile strength experimental results with the values obtained through the relationship defined in Eurocode 2 [20]. This shows a proximity between those pairs of values. Furthermore, part of the concrete mixes had tensile strength values slightly higher than those defined in Eurocode 2 [20].

Table 10. Splitting tensile strength and compressive strength correlation according to Eurocode 2 [20] (28 and 91 days).

\begin{tabular}{|c|c|c|c|c|c|c|}
\hline \multirow{4}{*}{ Mix. } & \multicolumn{3}{|c|}{28 days } & \multicolumn{3}{|c|}{91 days } \\
\hline & \multirow{2}{*}{$\begin{array}{c}\begin{array}{c}\text { Average } \\
\text { Compressive } \\
\text { Strength }\end{array} \\
f_{c m, c y l, 28 d}\end{array}$} & \multicolumn{2}{|c|}{$\begin{array}{c}\text { Average Splitting Tensile } \\
\text { Strength }\end{array}$} & \multirow{2}{*}{$\begin{array}{c}\begin{array}{c}\text { Average } \\
\text { Compressive } \\
\text { Strength }\end{array} \\
f_{c m, c y l, 91 d}\end{array}$} & \multicolumn{2}{|c|}{$\begin{array}{c}\text { Average Splitting Tensile } \\
\text { Strength }\end{array}$} \\
\hline & & $\begin{array}{c}\text { EC2 } \\
\text { Value }\end{array}$ & $\begin{array}{l}\text { Experimental } \\
\text { Values }\end{array}$ & & $\begin{array}{c}\text { EC2 } \\
\text { Value }\end{array}$ & $\begin{array}{c}\text { Experimental } \\
\text { Values }\end{array}$ \\
\hline & & (MPa) & & & (MPa) & \\
\hline $100 \%$ NA & 78.9 & 4.6 & 5.6 & 85.9 & 4.8 & 6.2 \\
\hline $25 \%$ RA & 75.2 & 4.5 & 5.0 & 82.3 & 4.7 & 5.8 \\
\hline $50 \%$ RA & 69.9 & 4.4 & 4.3 & 79.3 & 4.6 & 5.3 \\
\hline $100 \%$ RA & 61.0 & 4.2 & 3.8 & 65.8 & 4.3 & 4.3 \\
\hline $100 \%$ CRA & 71.1 & 4.4 & 4.5 & 80.7 & 4.7 & 5.5 \\
\hline $100 \%$ FRA & 65.9 & 4.3 & 4.0 & 73.3 & 4.5 & 5.0 \\
\hline
\end{tabular}

Figure 23 shows the relationship between uniaxial compressive strength and splitting tensile strength. Considering the high coefficient of variation $\left(R^{2}=0.94\right.$ and $\left.R^{2}=0.97\right)$, a strong correlation existed between these two properties. 


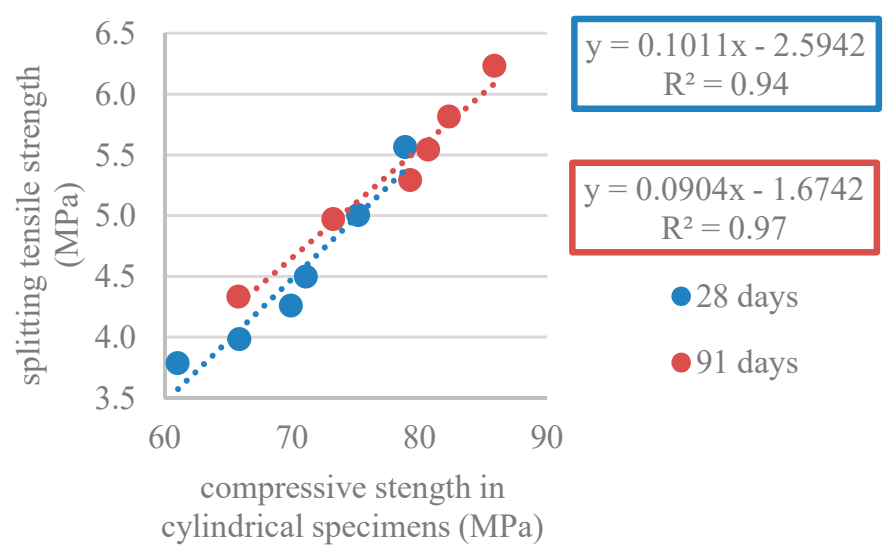

Figure 23. Splitting tensile strength and compressive strength correlation in cylindrical specimens (28 and 91 days).

\subsubsection{Secant Modulus of Elasticity}

Table 11 and Figure 24 show the results obtained in the secant modulus of elasticity test $\left(E_{c m}\right)$.

Table 11. Secant modulus of elasticity results (28 and 91 days).

\begin{tabular}{|c|c|c|c|c|c|c|c|c|}
\hline \multirow{3}{*}{ Mix. } & \multicolumn{4}{|c|}{28 days } & \multicolumn{4}{|c|}{91 days } \\
\hline & $E_{c m, 28 d}$ & S.D. & C.V. & $\Delta_{100} \%$ NA & $E_{c m, 91 d}$ & S.D. & C.V. & $\Delta_{100} \%$ NA \\
\hline & \multicolumn{2}{|c|}{ (MPa) } & $(\%)$ & $(\%)$ & \multicolumn{2}{|c|}{ (MPa) } & $(\%)$ & $(\%)$ \\
\hline $100 \%$ NA & 41.7 & 2.2 & 5.3 & 0.0 & 42.8 & 1.4 & 3.3 & 0.0 \\
\hline $25 \%$ RA & 39.6 & 1.5 & 3.8 & -4.9 & 41.2 & 1.9 & 4.6 & -3.8 \\
\hline $50 \%$ RA & 36.6 & 0.7 & 1.9 & -12.3 & 38.3 & 0.2 & 0.5 & -10.5 \\
\hline $100 \%$ RA & 30.8 & 6.3 & 20.5 & -26.1 & 34.2 & 0.2 & 0.6 & -20.1 \\
\hline $100 \%$ CRA & 37.0 & 0.6 & 1.6 & -11.2 & 39.5 & 0.8 & 2.0 & -7.8 \\
\hline $100 \%$ FRA & 32.8 & 0.1 & 0.3 & -21.4 & 36.8 & 1.0 & 2.7 & -13.9 \\
\hline
\end{tabular}

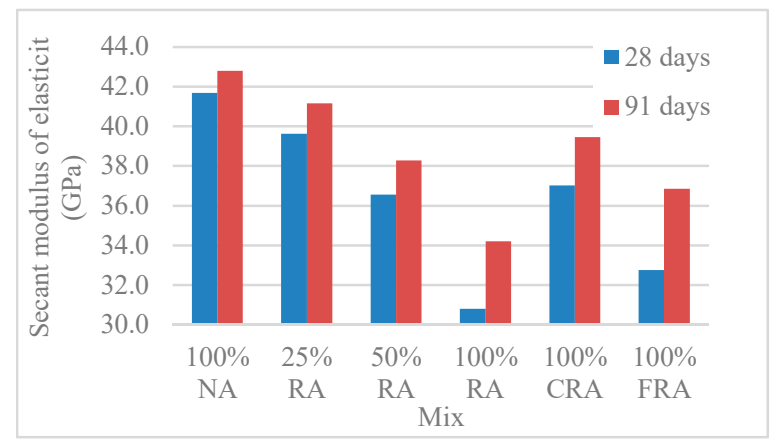

Figure 24. Secant modulus of elasticity results (28 and 91 days).

There was a decrease of the modulus of elasticity as the incorporation of RA increased, with maximum variations of $26 \%$ and $20 \%$ at 28 and 91 days, respectively (for the $100 \%$ RA mix). It is noteworthy that Pereira-de-Oliveira et al. [54] achieved a $25 \%$ reduction to the $100 \%$ RA mix at 28 days.

The modulus of elasticity reduction is explained by the lower RA's stiffness (compared to the NA's), due to the presence of old mortar adhered to the aggregates and to the lower deformability of that old mortar [54]. Comparing the 100\% NA mix with the 100\% CRA mix, there was a reduction of $11 \%$ and $8 \%$ at 28 and 91 days, respectively. Under similar conditions, Uygunoğlu et al. [60] achieved a reduction of about $14 \%$ at 28 days. The authors justified this using the longer shape of CRA (compared to CNA) and the weaker bond between the cement matrix and CRA. 
To calculate the modulus of elasticity $\left(E_{c m}\right)$, from the compressive strength experimental values in cylinders $\left(f_{c m, c y l}\right)$, Equation (3), proposed in Table 3.1 of Eurocode 2 [20], was used:

$$
E_{c m}=22\left[\left(f_{c m, c y l}\right) / 10\right]^{0.3}
$$

In Table 12, the experimental results of the modulus of elasticity are compared with those obtained through the relationship defined in Eurocode 2 [20].

Table 12. Secant modulus of elasticity and compressive strength correlation according to Eurocode 2

[20] in cylindrical specimens (28 and 91 days).

\begin{tabular}{|c|c|c|c|c|c|c|}
\hline \multirow{4}{*}{ Mix. } & \multicolumn{3}{|c|}{28 days } & \multicolumn{3}{|c|}{91 days } \\
\hline & \multirow{2}{*}{$\begin{array}{c}\text { Average } \\
\text { Compressive } \\
\text { Strength }\end{array}$} & \multicolumn{2}{|c|}{$\begin{array}{l}\text { Secant Modulus of } \\
\text { Elasticity }\end{array}$} & \multirow{2}{*}{$\begin{array}{c}\text { Average } \\
\text { Compressive } \\
\text { Strength }\end{array}$} & \multicolumn{2}{|c|}{$\begin{array}{l}\text { Secant Modulus of } \\
\text { Elasticity }\end{array}$} \\
\hline & & $\begin{array}{c}\text { EC2 } \\
\text { Value }\end{array}$ & $\begin{array}{l}\text { Experimental } \\
\text { Values }\end{array}$ & & $\begin{array}{c}\text { EC2 } \\
\text { Value }\end{array}$ & $\begin{array}{c}\text { Experimental } \\
\text { Values }\end{array}$ \\
\hline & (MPa) & \multicolumn{2}{|c|}{ (GPa) } & (MPa) & \multicolumn{2}{|c|}{ (GPa) } \\
\hline $100 \%$ NA & 78.9 & 40.9 & 41.7 & 85.9 & 41.9 & 42.8 \\
\hline $25 \%$ RA & 75.2 & 40.3 & 39.6 & 82.3 & 41.4 & 41.2 \\
\hline $50 \%$ RA & 69.9 & 39.4 & 36.6 & 79.3 & 40.9 & 38.3 \\
\hline $100 \%$ RA & 61.0 & 37.9 & 30.8 & 65.8 & 38.7 & 34.2 \\
\hline $100 \%$ CRA & 71.1 & 39.6 & 37.0 & 80.7 & 41.2 & 39.5 \\
\hline $100 \%$ FRA & 65.9 & 38.7 & 32.8 & 73.3 & 40.0 & 36.8 \\
\hline
\end{tabular}

Table 12 shows the proximity of the experimental modulus of elasticity with that obtained through the relationship defined in Eurocode 2 [20]. Most concretes mixes had modulus of elasticity values slightly lower than those defined in Eurocode 2 [20].

Figures 25 and 26 show the correlations obtained between the modulus of elasticity and compressive strength in cylindrical and cube specimens. $R^{2}$ values of 0.99 and 0.95 (for compressive strength in cylinders) and 0.91 and 0.96 (for compressive strength in cubes) were obtained.

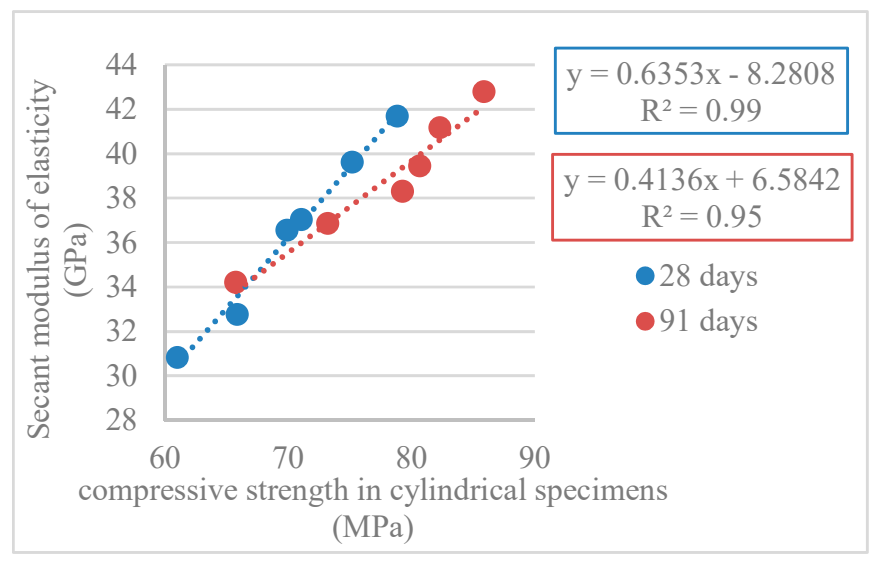

Figure 25. Secant modulus of elasticity and compressive strength correlation in cylindrical specimens (28 and 91 days). 


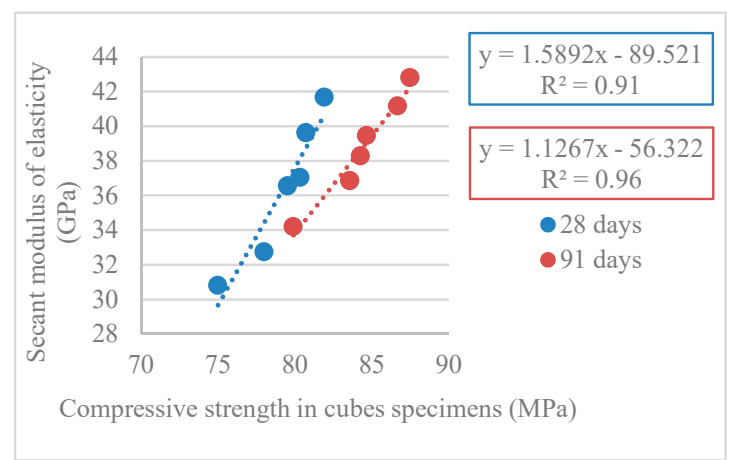

Figure 26. Secant modulus of elasticity and compressive strength correlation in cubes specimens (28 and 91 days).

\subsubsection{Ultrasonic Pulse Velocity}

Table 13 and Figure 27 show the results obtained in the ultrasonic pulse velocity test $\left(V_{u s m, c}\right)$.

Table 13. Ultrasonic pulse velocity (7, 28, and 91 days).

\begin{tabular}{|c|c|c|c|c|c|c|c|c|c|}
\hline \multirow{3}{*}{ Mix. } & \multicolumn{3}{|c|}{7 days } & \multicolumn{3}{|c|}{28 days } & \multicolumn{3}{|c|}{91 days } \\
\hline & $V_{u s m, c, 7 d}$ & S.D. & $\Delta_{100 \%}$ NA & $V_{u s m, c, 28 d}$ & S.D. & $\Delta_{100 \%}$ NA & $V_{u s m, c, 91 d}$ & S.D. & $\Delta_{100} \% \mathrm{NA}$ \\
\hline & \multicolumn{2}{|c|}{$(\mathrm{m} / \mathrm{s})$} & $(\%)$ & \multicolumn{2}{|c|}{$(\mathrm{m} / \mathrm{s})$} & $(\%)$ & \multicolumn{2}{|c|}{$(\mathrm{m} / \mathrm{s})$} & $(\%)$ \\
\hline $\begin{array}{l}100 \% \\
\text { NA }\end{array}$ & 4907.6 & 53.0 & 0.0 & 5030.7 & 4.0 & 0.0 & 5123.8 & 58.6 & 0.0 \\
\hline $25 \%$ RA & 4843.0 & 74.7 & -1.3 & 4961.9 & 69.6 & -1.4 & 5037.6 & 46.2 & -1.7 \\
\hline $50 \%$ RA & 4623.3 & 19.7 & -5.8 & 4819.8 & 29.9 & -4.2 & 4937.8 & 12.5 & -3.6 \\
\hline $\begin{array}{c}100 \% \\
\text { RA }\end{array}$ & 4474.7 & 18.0 & -8.4 & 4624.9 & 17.2 & -8.1 & 4702.3 & 30.6 & -8.2 \\
\hline $\begin{array}{l}100 \% \\
\text { CRA }\end{array}$ & 4779.3 & 59.5 & -2.6 & 4932.4 & 11.3 & -2.0 & 4972.4 & 26.2 & -3.0 \\
\hline $\begin{array}{l}100 \% \\
\text { FRA }\end{array}$ & 4587.2 & 16.2 & -6.5 & 4755.2 & 5.8 & -5.5 & 4851.5 & 64.9 & -5.3 \\
\hline
\end{tabular}

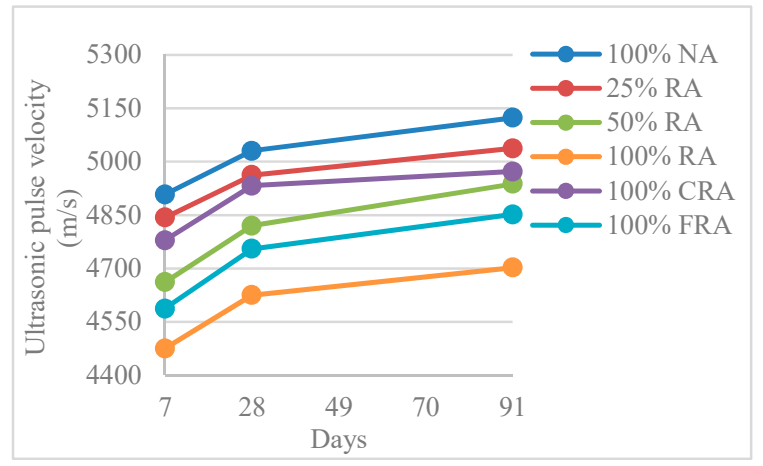

Figure 27. Ultrasonic pulse velocity $(7,28$, and 91 days).

The $V_{u s m, c}$ decreased with the increased RA incorporation ratio. Thus, the reference mix $(100 \%$ NA) had a higher $V_{u s m, c}$, reaching $5124 \mathrm{~m} / \mathrm{s}$ at 91 days. On the other hand, compared with the $100 \%$ NA mix, the $100 \%$ RA mix had a lower $V_{u s m, c}$ by $8 \%$.

The reduction in $V_{u s m, c}$ with the use of RA can be explained by the RA nature, i.e., higher porosity when compared to NA (due to the adhered old mortar).

Tuyan et al. [56] obtained results with the same trends, with $4 \%$ loss in pulse velocity for mixes with $60 \%$ replacement of NA with RA.

Malhotra [61] proposed a classification system for concrete quality as a $V_{u s m, c}$ function where, with the values obtained in the present work (3660-4580 m/s range), we can classify all mixtures as 
"good". With this classification, it was possible to estimate that none of the mixes had significant voids, volumes, or cracks that may have compromised its performance.

Figure 28 shows the linear relationship between pulse velocity and density $\left(R^{2}=0.97 ; R^{2}=0.91\right.$; $\left.R^{2}=0.96\right)$. Thus, the denser the concrete, the faster the waves propagated (higher pulse velocity speed).

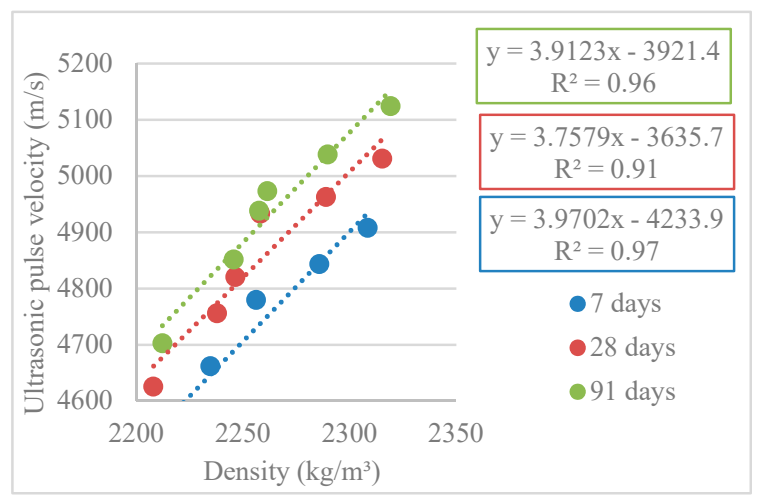

Figure 28. Density and ultrasonic pulse velocity correlation $(7,28$, and 91 days).

Figure 29 shows the linear relationship between pulse velocity and modulus of elasticity $\left(R^{2}=0.94\right.$; $\left.R^{2}=0.99\right)$.

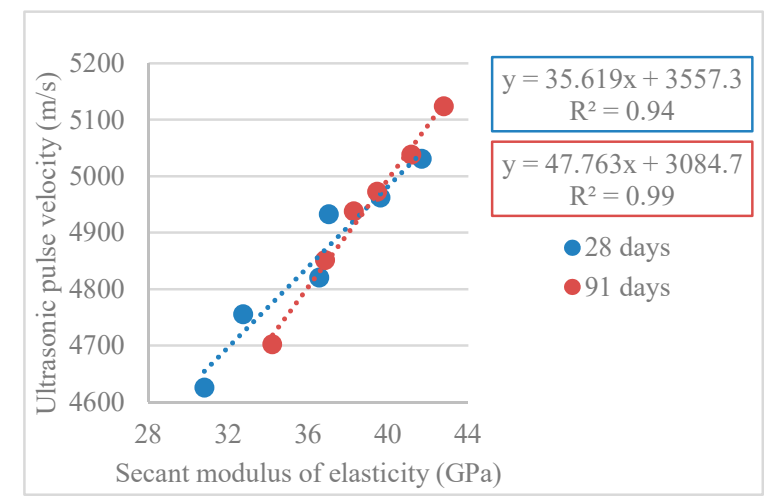

Figure 29. Secant modulus of elasticity and ultrasonic pulse velocity correlation (28 and 91 days).

These trends were confirmed by Bogas et al. [33], who stated that the main physical properties that influence ultrasonic pulse velocity are density and modulus of elasticity.

\subsubsection{Abrasion Resistance}

Table 14 and Figure 30 show the thickness reduction by abrasion results. Figure 30 shows a trend for a greater thickness reduction as the RA substitution ratio increases, which was consistent with the trends in other mechanical parameters studied (compressive strength and modulus of elasticity). The greatest thickness reduction (39\%) occurred in the 100\% RA mix. In the case of conventional concrete with 100\% RA, Barbudo et al. [62] and Lotfi et al. [63] achieved thickness reductions of 17\% and $40 \%$, respectively. This is explained by the more porous nature of RA and the adhered old mortar.

Comparing the reference (100\% NA) and 100\% FRA mixes, a thickness reduction of $36 \%$ occurred. Pereira et al. [64] achieved thickness reductions of the same order of magnitude. For conventional concrete with RA, $21 \%, 37 \%$, and $50 \%$ thickness reduction was achieved for concrete without $S_{p}$, with conventional $S_{p}$, and with high-range $S_{p}$, respectively. This thickness reduction is explained by the increase in the effective w/c ratio observed in FRA concrete, as well as the higher porosity of RA. 
Table 14. Abrasion resistance: Wear depth (91 days).

\begin{tabular}{cccc}
\hline \multirow{2}{*}{ Mix. } & Wear Depth & S.D. & $\boldsymbol{\Delta}_{\mathbf{1 0 0} \%}$ NA \\
\cline { 2 - 4 } & & $\mathbf{( m m )}$ & $\mathbf{( \% )}$ \\
\hline 100\% NA & 3.0 & 0.1 & 0.0 \\
25\% RA & 3.1 & 0.2 & 4.5 \\
$50 \%$ RA & 3.3 & 0.1 & 12.8 \\
100\% RA & 4.1 & 0.1 & 38.6 \\
100\% CRA & 3.3 & 0.1 & 10.2 \\
100\% FRA & 4.0 & 0.3 & 36.2 \\
\hline
\end{tabular}

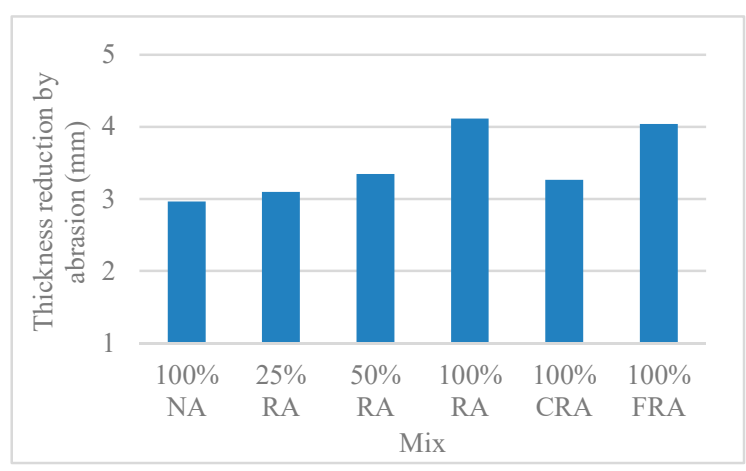

Figure 30. Abrasion resistance: Thickness reduction (91 days).

\subsubsection{Shrinkage}

Figure 31 shows the results obtained for the shrinkage evolution over 91 days $\left(\varepsilon_{c s}\right)$.

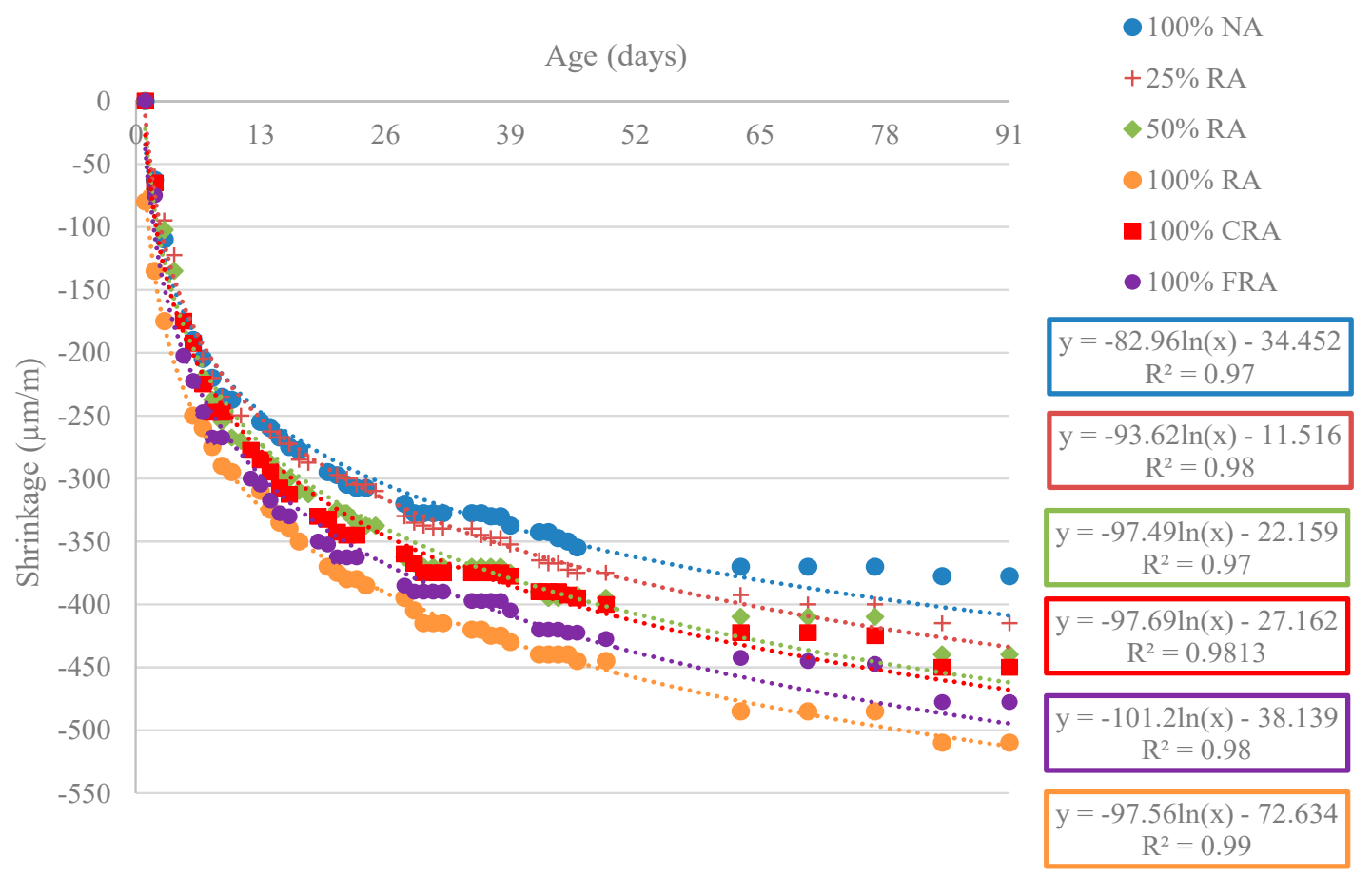

Figure 31. Evolution of shrinkage over 91 days.

For all mixes, Figure 31 shows that the shrinkage increased nonlinearly over time, as expected. Rapid growth was observed during the early days, which subsequently tended to stabilize. The use of logarithmic regressions led to very high correlation coefficients $\left(R^{2}\right)$ (between 0.97 and 0.99 ). 
Cartuxo et al. [65] found that the shrinkage increases analogously and obtained correlation coefficients greater than 0.95 .

Replacing NA with RA led to a decrease in the performance of all mixes. Thus, the $100 \%$ RA mix showed the highest shrinkage strain value, with an increase over the reference SCC of $35 \%$ at 91 days. However, the values were well below those obtained by Kou and Poon [59], who recorded shrinkage increases of $166 \%(\mathrm{w} / \mathrm{c}=0.53)$ and $103 \%(\mathrm{w} / \mathrm{c}=0.44)$ for $100 \%$ RA replacement at 91 days. The authors justified these results with the RA higher porosity and consequent lower density that decreased their stiffness and ability to restrict strains.

Table 15 shows the shrinkage strains values at 7, 28, and 91 days. Thus, it is possible to analyze the behaviour of high-performance self-compacting concrete with recycled aggregates (HPSCCRA) in terms of shrinkage at young and older ages. The results show distinct behaviours over time.

Table 15. Shrinkage (7, 28, and 91 days).

\begin{tabular}{|c|c|c|c|c|c|c|}
\hline \multirow{3}{*}{ Mix. } & \multicolumn{2}{|c|}{7 Days } & \multicolumn{2}{|c|}{28 Days } & \multicolumn{2}{|c|}{91 Days } \\
\hline & $\varepsilon_{c s, 7 d}$ & $\Delta_{100 \%} \mathrm{NA}$ & $\varepsilon_{c s, 28 d}$ & $\Delta_{100 \%} \mathrm{NA}$ & $\varepsilon_{c s, 91 d}$ & $\Delta_{100 \%}$ NA \\
\hline & $(\mu \mathrm{m} / \mathrm{m})$ & $(\%)$ & $(\mu \mathrm{m} / \mathrm{m})$ & $(\%)$ & $(\mu \mathrm{m} / \mathrm{m})$ & $(\%)$ \\
\hline $100 \%$ NA & -205.0 & 0.0 & -320.0 & 0.0 & -377.5 & 0.0 \\
\hline $25 \%$ RA & -205.0 & 0.0 & -330.0 & 3.1 & -415.0 & 9.9 \\
\hline $50 \%$ RA & -220.0 & 7.3 & -362.5 & 13.3 & -440.0 & 16.6 \\
\hline $100 \%$ RA & -260.0 & 26.8 & -395.0 & 23.4 & -510.0 & 35.1 \\
\hline $100 \%$ CRA & -225.0 & 9.8 & -360.0 & 12.5 & -450.0 & 19.2 \\
\hline $100 \%$ FRA & -247.5 & 20.7 & -385.0 & 20.3 & -477.5 & 26.5 \\
\hline
\end{tabular}

Table 15 shows that shrinkage strain tended to increase with age (comparing RA mixes with the reference mix), e.g., $50 \%$ RA versus $100 \%$ NA showed increases in strain of $7 \%, 13 \%$, and $15 \%$ at 7,28 , and 91 days, respectively. This phenomenon is explained by the internal curing carried out by RA, which allows the evaporation water to be compensated by existing water in RA. Thus, as long as water is available inside RA, the dimensional shrinkage variations are reduced [66].

For the shrinkage strain calculation $\left(\varepsilon_{\mathrm{cs}}\right)$ from the compressive strength experimental values in cylinders $\left(\mathrm{f}_{\mathrm{cm}}\right)$, the equation for conventional concrete's shrinkage proposed in Eurocode 2 [20] was used. For the sake of readability, the total shrinkage strain values of the conventional mixes (estimated according to the equation proposed in part 1-1 (General rules and rules for buildings) of Eurocode 2 [20] and shown in Table 16 and Figure 32) only corresponded to the average stresses obtained by HPSCC produced in cylindrical specimens at 28 and 91 days. The seven-day values were calculated with a $f_{c m, c y l} / f_{c m, c}$ ratio of approximately 0.82 .

Table 16. Evolution of shrinkage: Experimental values and based on Eurocode 2 [20] as a function of compressive strength at 7,28 , and 91 days.

\begin{tabular}{|c|c|c|c|c|c|c|}
\hline \multirow{3}{*}{ Mix. } & \multicolumn{2}{|c|}{7 Days } & \multicolumn{2}{|c|}{28 Days } & \multicolumn{2}{|c|}{91 Days } \\
\hline & EC2 Value & $\varepsilon_{c s, 7 d}$ & EC2 Value & $\varepsilon_{c s, 28 d}$ & EC2 Value & $\varepsilon_{c s, 91 d}$ \\
\hline & \multicolumn{2}{|c|}{$(\mu \mathrm{m} / \mathrm{m})$} & \multicolumn{2}{|c|}{$(\mu \mathrm{m} / \mathrm{m})$} & \multicolumn{2}{|c|}{$(\mu \mathrm{m} / \mathrm{m})$} \\
\hline $100 \%$ NA & -142.5 & -205.0 & -316.5 & -320.0 & -460.2 & -377.5 \\
\hline $25 \%$ RA & -142.0 & -205.0 & -319.4 & -330.0 & -466.0 & -415.0 \\
\hline $50 \%$ RA & -141.5 & -220.0 & -324.3 & -362.5 & -475.4 & -440.0 \\
\hline $100 \%$ RA & -141.5 & -260.0 & -334.4 & -395.0 & -493.9 & -510.0 \\
\hline $100 \%$ CRA & -141.6 & -225.0 & -323.2 & -360.0 & -473.2 & -450.0 \\
\hline $100 \%$ FRA & -141.4 & -247.5 & -328.6 & -385.0 & -483.3 & -477.5 \\
\hline
\end{tabular}




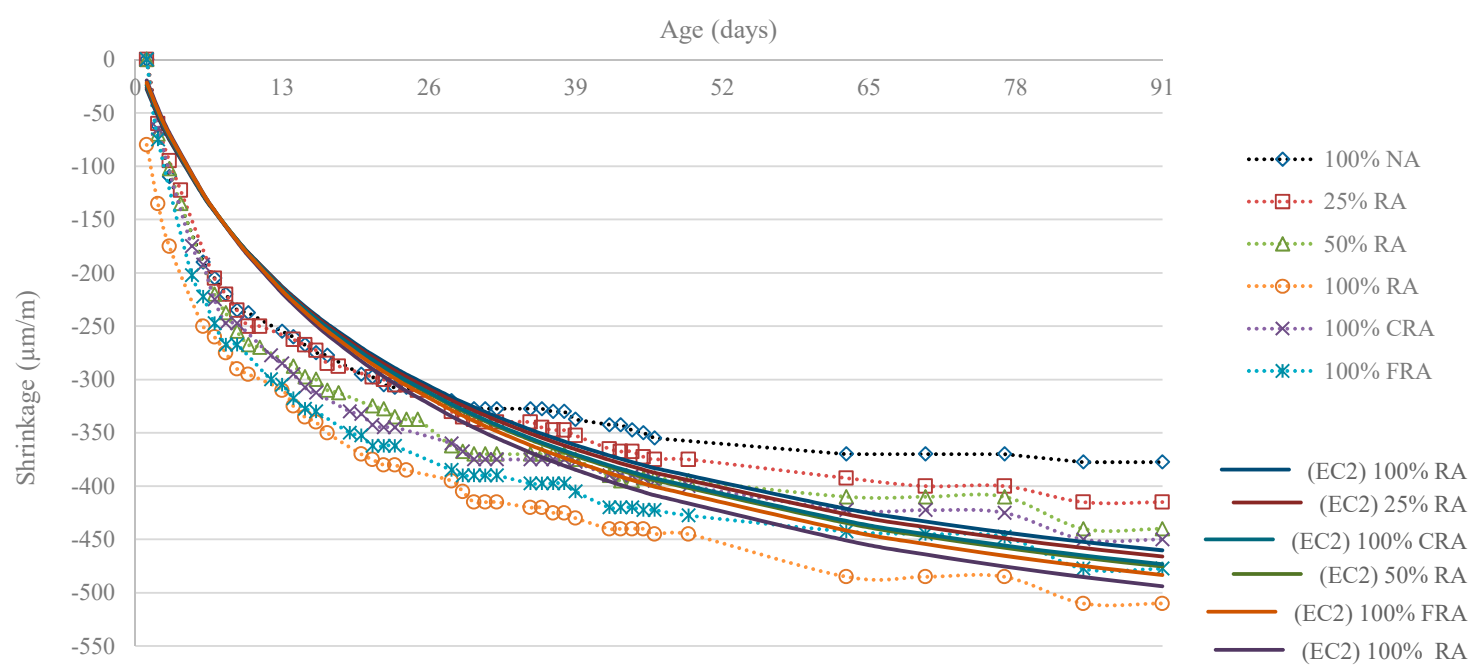

Figure 32. Evolution of shrinkage over 91 days: experimental values and based on EUROCODE 2 [20] values.

In Table 16 and Figure 32, the experimental results of shrinkage strain are compared with those obtained through the relationship defined in Eurocode 2 [20].

Figure 32 shows that the prediction model proposed by Eurocode 2 [20] presented shrinkage strains lower than the experimental strains (for example, at seven days, the difference between the experimental strain and the predicted strain through Eurocode 2 [20] was, on average, $85 \mu \mathrm{m} / \mathrm{m}$ ). In contrast, at older ages (91 days), the Eurocode 2 prediction model [20] results generally tended to be close to the experimental results (for example, at 91 days, the difference between experimental strain and the predicted strain through Eurocode 2 [20] was, on average, $30 \mu \mathrm{m} / \mathrm{m}$ ). For older ages, it was also found that the prediction model proposed by Eurocode 2 [20] tended to underestimate shrinkage strain (with the exception of the $100 \%$ RA mix).

Thus, the prediction model proposed by Eurocode 2 [20] cannot predict shrinkage strain at early ages, but tended to be similar in the long-term the strains. This was also found by Silva and de Brito [28].

The results of shrinkage strain agreed with those of the modulus of elasticity test. Mixes with RA had a lower modulus of elasticity than the reference mix (NA only). Compared to NA, the lower stiffness of RA decreased the overall stiffness of the mixes and thus increased the shrinkage strain.

Figure 33 shows the relationship between the modulus of elasticity and shrinkage $\left(R^{2}=0.85\right)$.

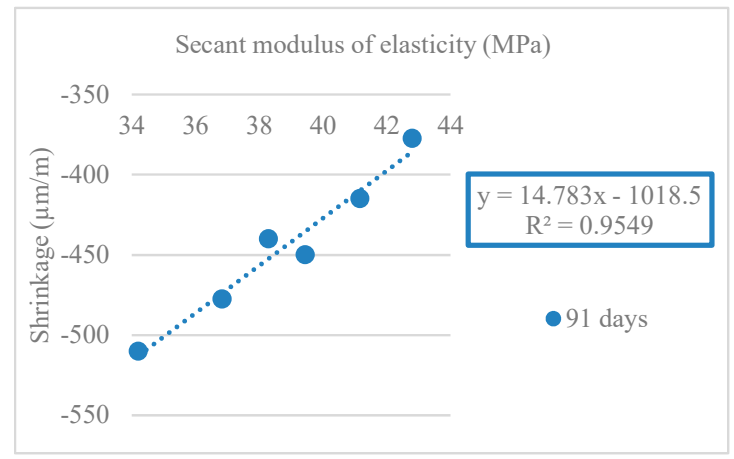

Figure 33. Shrinkage and secant modulus of elasticity correlation (91 days).

Figure 34 shows the correlation between shrinkage deformation and compressive strength at 91 days. The results led to the conclusion that there was a linear trend of shrinkage decrease with increasing compressive strength $\left(R^{2}=0.94\right)$. 


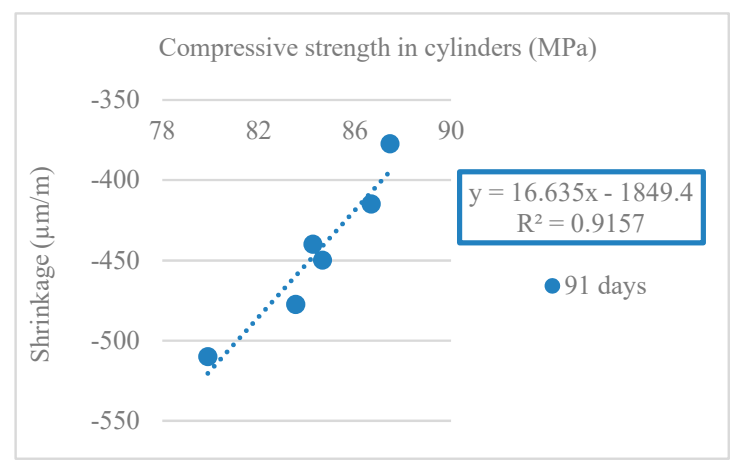

Figure 34. Shrinkage and compressive strength in cylinders correlation (91 days).

\subsubsection{Creep}

For the determination of creep strain, the concrete specimens were loaded at 28 days for 91 days. Figure 35 shows the results obtained for creep strain.

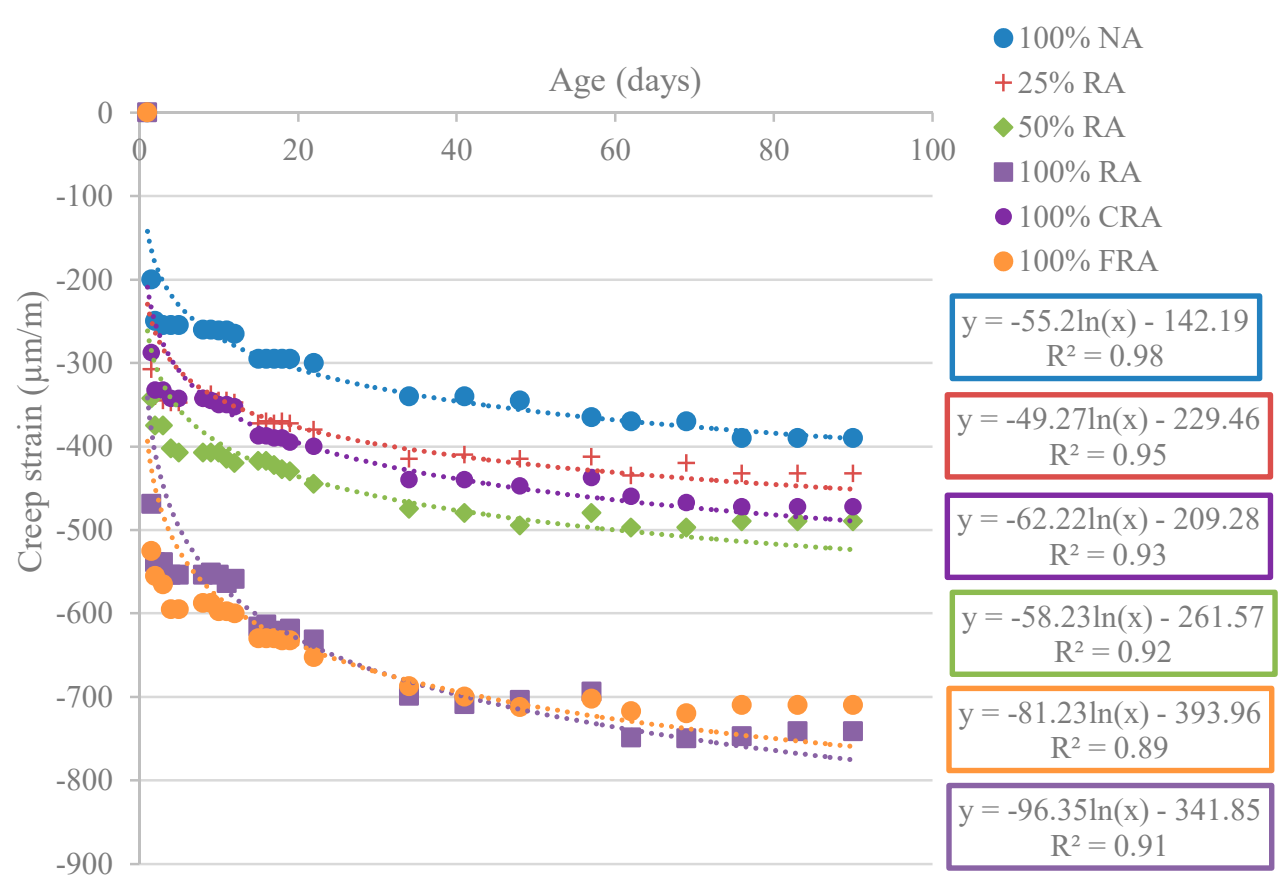

Figure 35. Creep strain over 91 days.

As with shrinkage, creep increased nonlinearly over time (Figure 35). The use of logarithmic regressions led to high correlation coefficients $\left(R^{2}\right)$ (between 0.85 and 0.95). The creep phenomenon took place mainly at early ages, translating into a rapid growth of the strain in the early days which tended to stabilize afterward.

The obtained results showed that the creep strain increased with the substitution ratio of NA with RA, leading to a reduction in concrete performance. The increase in creep with increasing RA replacement was due to the reduction of the elastic modulus of RA relative to NA. RA have a lower stiffness and therefore a lower ability to resist the creep phenomenon.

Mixes with 50\% RA and 100\% CRA showed an increase in creep strain of $34 \%$ and $30 \%$, respectively (compared to 100\% NA). Manzi et al. [67] achieved a creep strain increase of $15 \%$ for concretes with 50\% RA incorporation. Domingo-Cabo et al. [68] observed a 51\% increase in creep strain for $100 \%$ CRA mix. The authors justified this behaviur with the smaller modulus of elasticity of RA compared to NA's.

Table 17 shows the creep strain coefficients for all mixes. All mixes had very close creep strain coefficients. 
Table 17. Creep strain coefficient (91 days).

\begin{tabular}{|c|c|c|c|c|c|}
\hline \multirow[t]{2}{*}{ Mix. } & $\begin{array}{c}\text { Creep at } 91 \\
\text { days (Without } \\
\text { Shrinkage) }\end{array}$ & $E_{c m, 91 d}$ & $\begin{array}{c}\text { Instantaneous } \\
\text { Creep }\end{array}$ & Final Creep & \multirow[t]{2}{*}{$\begin{array}{c}\text { Creep } \\
\text { Coefficient }\end{array}$} \\
\hline & $(\mu \mathrm{m} / \mathrm{m})$ & (MPa) & $(\mu \mathrm{m} / \mathrm{m})$ & $(\mu \mathrm{m} / \mathrm{m})$ & \\
\hline $100 \%$ NA & $-3.90 \times 10^{-4}$ & 41682 & $2.40 \times 10^{-4}$ & $1.50 \times 10^{-4}$ & 0.63 \\
\hline $25 \%$ RA & $-4.33 \times 10^{-4}$ & 39622 & $2.52 \times 10^{-4}$ & $1.80 \times 10^{-4}$ & 0.71 \\
\hline $50 \%$ RA & $-4.90 \times 10^{-4}$ & 36556 & $2.74 \times 10^{-4}$ & $2.16 \times 10^{-4}$ & 0.79 \\
\hline $100 \%$ RA & $-7.41 \times 10^{-4}$ & 30806 & $3.25 \times 10^{-4}$ & $4.17 \times 10^{-4}$ & 1.28 \\
\hline $100 \%$ CRA & $-4.73 \times 10^{-4}$ & 37032 & $2.70 \times 10^{-4}$ & $2.02 \times 10^{-4}$ & 0.75 \\
\hline $100 \%$ FRA & $-7.10 \times 10^{-4}$ & 32751 & $3.05 \times 10^{-4}$ & $4.05 \times 10^{-4}$ & 1.33 \\
\hline
\end{tabular}

Figure 36 shows a linear relationship between creep strain and modulus of elastic $\left(\mathrm{R}^{2}=0.87\right)$. In Figure 37, there is a linear relationship between creep and compressive strength $\left(\mathrm{R}^{2}=0.88\right)$.

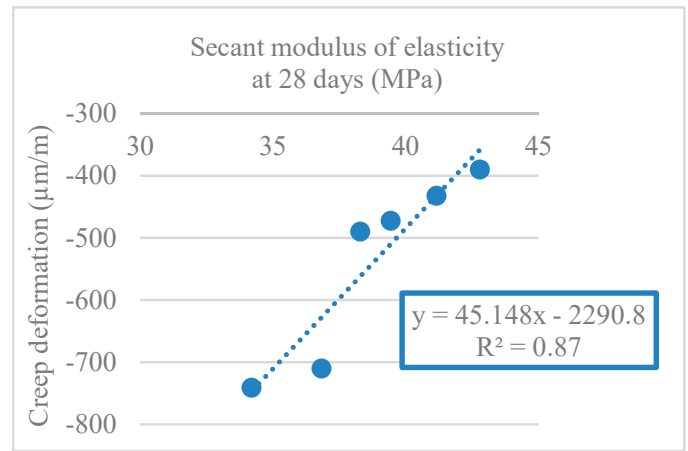

Figure 36. Creep strain and secant modulus of elasticity correlation (28 days).

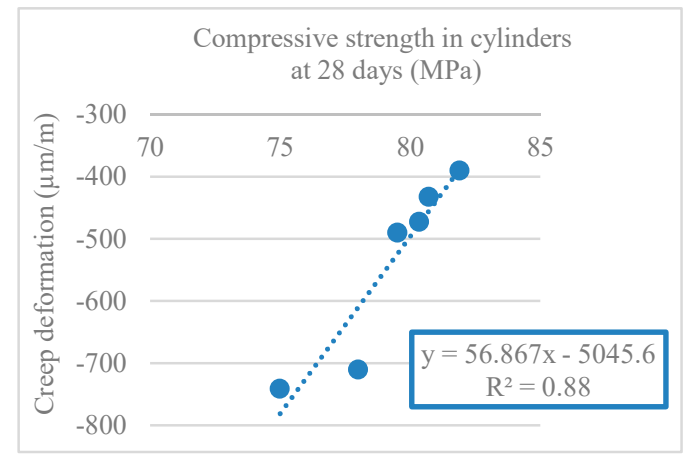

Figure 37. Creep strain and compressive strength in cylinders correlation (28 days).

\subsection{Global Analysis of Results}

Replacing NA with AR caused decreased compressive strength and splitting tensile strength. This is explained by the poorer quality of RA due to their adhered mortar, which is responsible for increasing the porosity and cracking of RA, thus weakening the transition zone connections between RA and the new cement binder. At 28 days, there was a decrease of $1-8 \%$ in cubic compressive strength, 5-23\% in cylindrical compressive strength, and 10-32\% on splitting tensile strength.

According to the classification of NP EN 206-1 [2], the 100\% RA mix belonged to class strength C50/60 and the remaining mixes belonged to a higher class, C65/67. Thus, all mixes can be classified as high performance (HPSCC).

There was a decrease in the modulus of elasticity with the increase of RA incorporation, which is explained by the lower RA's stiffness (compared to NA) due to the presence of adhered old mortar in RA and to the lower deformability of the mortar. 
The lower RA stiffness decreased the overall concrete stiffness and thus increased the shrinkage and creep strain. The shrinkage and creep increases at 91 days were higher than those at 7 days due to the internal healing phenomenon triggered by RA.

Ultrasonic pulse velocity decreased with increasing RA replacement ratio. This decrease was small ( $1 \%$ to $8 \%$, at 28 days) and is explained by RA's quality, i.e., higher porosity than NA.

There was an increase of the thickness reduction by abrasion as the RA replacement ratio increased (at 28 days a thickness reduction up to $39 \%$ occurred).

Eurocode 2 [20] provides equations to estimate the properties of conventional concrete based on experimental results of compressive strength in cylinders obtained at 28 days. Thus, these equations were used to estimate other properties (splitting tensile strength, secant modulus of elasticity, and shrinkage strain) and were compared with the experimental results.

Comparing the experimental results with those obtained through the Eurocode 2 [20] equations, the prediction models tended to provide values reasonably close to those obtained experimentally.

\section{Concluding Remarks}

This work intended to analyze the experimental results obtained in the production of HPSCC with recycled aggregates and to validate its viability regarding mechanical properties. Six types of HPSCC were produced incorporating different amounts of RA. Five replacement ratios of FRA and CRA (FRA/CRA) were considered $(25 / 25 \% ; 50 / 50 \% ; 100 / 100 \% ; 0 / 100 \%$, and $100 / 0 \%$ ) in addition to a reference mix (FRA/CRA) of $0 / 0 \%$.

The results of the fresh-state properties showed that all mixes fulfilled the workability parameters required by NP EN 206-9 [39]. Thus, all the produced mixes had the required characteristics for SCC.

The results showed that the different mixes incorporating RA presented coherent performance variations between themselves and when compared with results of other authors.

For the maximum replacement ratio $(100 \% \mathrm{RA})$, the compressive strength and modulus of elasticity showed performance losses of no more than $26 \%$.

The $25 \%$ RA mix had the best performance, with mechanical properties losses of less than $10 \%$.

For all mechanical properties under analysis, the 50\% RA and 100\% CRA mixes had similar performances. Additionally, the first tended to have worse results than the second.

The 100\% FRA mix presented a less favorable performance than the 100\% RA mix. Comparing these two mixes, both had 100\% FRA instead of FNA, differing only in the nature of coarse aggregates (with 100\% CNA and 100\% CRA respectively). Therefore, the differences may be justified by the nature of $\mathrm{CA}$ and the water they absorbed.

There is a need to correct the amounts of mixing water due to the high-water absorption of RA. This means that, particularly for CRA, the mixes can retain considerable amounts of water during the initial mixing phase. This water, which is not used for workability or any hydration process at an early age, is available for later release to contribute to the later reaction of FA with calcium oxide or calcium hydroxide (products resulting from cement hydration).

With these results, it is possible to confirm the viability of producing HPSCC with recycled aggregates from the precast industry. The mixes with incorporation ratios of $25 \% \mathrm{RA}, 50 \% \mathrm{RA}$, and $100 \%$ CRA are viable and have very interesting performance. The other mixes also perform well, with a performance reduction of less than $25 \%$.

Author Contributions: T.B. and P.R.d.S. conceived and designed the experiments; T.B. performed the experiments; P.R.d.S. and J.d.B. analysed and validated the methodology and results; T.B. and P.R.d.S. wrote the paper.

Acknowledgments: The authors gratefully acknowledge the support of the CERIS Research Institute, Instituto Superior Técnico of the University of Lisbon and FCT (Foundation for Science and Technology).

Conflicts of Interest: The authors declare no conflicts of interest. 


\section{References}

1. Hansen, T.C.; Boegh, E. Elasticity and drying shrinkage of recycled aggregate concrete. Am. Concr. Inst. J. $1985,82,648-652$.

2. Instituto Português da Qualidade-IPQ. NP EN 206-1, Concrete, Part 1: Specification, Performance, Production and Conformity; IPQ: Lisbon, Portugal, 2007; p. 84.

3. European Project Group-EPG; BIBM; CEMBUREAU; ERMCO; EFCA; EFNARC. The European Guidelines for Self-Compacting Concrete, Specification-Production and Use; EFNARC: Farnham, UK, 2005; p. 63.

4. Camões, A. High Performance Concrete with Fly Ash Incorporation (in Portuguese). Ph.D. Thesis, Universidade do Minho, Guimarães, Portugal, 2002; p. 456.

5. Tu, T.-Y.; Chen, Y.-Y.; Hwang, C.-L. Properties of HPC with recycled aggregates. Cem. Concr. Res. 2006, 36, 943-950. [CrossRef]

6. STA-Silica Fume Association. Silica Fume: User's Manual; U.S. Department of Transportation: Washington, DC, USA; Federal Highway Administration: Lovettsville, VA, USA; EUA: Etterbeek, Belgium, 2005; p. 183.

7. Parande, A.K. Role of Ingredients for High Strength and High Performance Concrete-A Review; CSIR-Central Electrochemical Research Institute Karaikudi: Tamil Nadu, India, 2013; p. 12.

8. Ramezanianpour, A.A.; Rezaei, H.R.; Savoj, H.R. Influence of Silica Fume on Chloride Diffusion and Corrosion Resistance of Concrete-A Review; Department of Civil and Environmental Engineering: Amir Kabir, Iran; University of Technology: Tehran, Iran, 2014; p. 21.

9. Hassan, K.E.; Cabrera, J.G.; Maliehe, R.S. The effect of mineral admixtures on the properties of high-performance concrete. Cem. Concr. Compos. 2000, 22, 267-271. [CrossRef]

10. Neville, A.; Aïtcin, P. High performance concrete-An overview. Mater. Struct. 1998, 31, 111-117. [CrossRef]

11. Roy, D. Advanced cement systems including CBC, DSP, MDF. In Proceedings of the 9th International Congress on the Chemistry of Cement, New Delhi, India, 23-28 November 1992; pp. 357-380.

12. Bharatkumar, B.H.; Narayanan, R.; Raghuprasad, B.K.; Ramachandramurthy, D.S. Mix proportioning of high performance concrete. Cem. Concr. Compos. 2001, 23, 71-80. [CrossRef]

13. Lim, C.H.; Yoon, Y.S.; Kim, J.H. Genetic algorithm in mix proportioning of high-performance concrete. Cem. Concr. Res. 2004, 34, 409-420. [CrossRef]

14. Aïtcin, P.C. The durability characteristics of high performance concrete: A review. Cem. Concr. Compos. 2003, 25, 409-420. [CrossRef]

15. American Concrete Institute-ACI. Guide for Selecting Proportions for High-Strength Concrete with Portland Cement and Fly Ash (ACI 211.4R); American Concrete Institute: Farmington Hills, MI, USA, 1993.

16. Aslani, F.; Ma, G.; Law Yim Wan, D.; Muselin, G. Development of high-performance self-compacting concrete using waste recycled concrete aggregates and rubber granules. J. Clean. Prod. 2018, 182, 553-566. [CrossRef]

17. Grdic, Z.J.; Toplicic-Curcic, G.A.; Despotovic, I.M.; Ristic, N.S. Properties of self-compacting concrete prepared with coarse recycled concrete aggregate. Constr. Build. Mater. 2010, 24, 1129-1133. [CrossRef]

18. Corinaldesi, V.; Moriconi, G. The role of industrial by-products in self-compacting concrete. Constr. Build. Mater. 2011, 25, 3181-3186. [CrossRef]

19. Santos, S.; Silva, P.R.; de Brito, J. Mechanical performance evaluation of self-compacting concrete with fine and coarse recycled aggregates from precast industry. Materials 2017, 10, 904. [CrossRef] [PubMed]

20. Instituto Português da Qualidade-IPQ. NP EN 1992-1, Eurocode 2, Design of Concrete Structures, Part 1-1: General Rules and Rules for Buildings; IPQ: Lisbon, Portugal, 2008; p. 259.

21. Instituto Português da Qualidade-IPQ. NP EN 197-1, A3, Cement, Part 1: Composition, Specifications and Conformity Criteria for Common Cements; IPQ: Lisbon, Portugal, 2008; p. 8.

22. Instituto Português da Qualidade-IPQ. NP EN 450-1, A1, Fly Ash for Concrete, Part 1: Definition, Specifications and Conformity Criteria; IPQ: Lisbon, Portugal, 2008; p. 35.

23. Instituto Português da Qualidade-IPQ. NP EN 450-2, 2006, Fly Ash for Concrete, Part 2: Conformity Evaluation; IPQ: Lisbon, Portugal, 2006; p. 29.

24. LNEC E 466. Limestone Fillers for Hydraulic Binders (in Portuguese); National Laboratory for Civil Engineering: Lisbon, Portugal, 2005; p. 2.

25. Instituto Português da Qualidade-IPQ. NP EN 13263-1:2005+A1:2009, Silica Fume for Concrete-Part 1: Definitions, Requirements and Conformity Criteria (Includes Amendment A1:2009); IPQ: Lisbon, Portugal, 2005; p. 25. 
26. Instituto Português da Qualidade-IPQ. NP EN 12620, Aggregates for Concrete; IPQ: Lisbon, Portugal, 2010; p. 61.

27. Instituto Português da Qualidade-IPQ. NP EN 934-1, Admixtures for Concrete, Mortar and Grout, Part 1: Common Requirements; IPQ: Lisbon, Portugal, 2008; p. 13.

28. Instituto Português da Qualidade-IPQ. NP EN 934-2, Admixtures for Concrete, Mortar and Grout, Part 2: Concrete Admixtures, Definitions, Requirements, Conformity, Marking and Labelling; IPQ: Lisbon, Portugal, 2009; p. 28.

29. Instituto Português da Qualidade-IPQ. NP EN 1008, Mixing Water for Concrete, Specification for Sampling, Testing and Assessing the Suitability of Water, Including Water Recovered from Processes in the Concrete Industry, as Mixing Water for Concrete; IPQ: Lisbon, Portugal, 2003; p. 22.

30. Instituto Português da Qualidade-IPQ. NP EN 196-6, Methods of Testing Cement_Part 6: Determination of Fineness; IPQ: Lisbon, Portugal, 2010; p. 20.

31. Nepomuceno, M.; Oliveira, L. Parameters for self-compacting concrete mortar phase. ACI Mater. J. 2008, 253, 323-340.

32. Nepomuceno, M.; Oliveira, L.; Lopes, S. Methodology for mix design of the mortar phase of self-compacting concrete using different mineral additions in binary blends of powders. Constr. Build. Mater. 2012, 26, 317-326. [CrossRef]

33. Bogas, J.; Gomes, A.; Pereira, M. Self-compacting lightweight concrete produced with expanded clay aggregate. Constr. Build. Mater. 2012, 35, 1013-1022. [CrossRef]

34. Nepomuceno, M.; Oliveira, L.; Lopes, S.M.R. Methodology for the mix de-sign of self-compacting concrete using different mineral additions in binary blends of powders. Constr. Build. Mater. 2014, 64, 82-94. [CrossRef]

35. Silva, P.R.; de Brito, J. Fresh-State Properties of Self-Compacting Mortar and Concrete with Combined Use of Limestone Filler and Fly Ash. Mater. Res. 2015, 18, 1097-1108. [CrossRef]

36. Nepomuceno, M.C.S.; Pereira-de-Oliveira, L.A.; Lopes, S.M.R.; Franco, R.M.C. Maximum coarse aggregate's volume fraction in self-compacting concrete for different flow restrictions. Constr. Build. Mater. 2016, 113, 851-856. [CrossRef]

37. Silva, P.R.; de Brito, J. Durability Performance of Self-Compacting Concrete (SCC) with Binary and Ternary Mixes of Fly Ash and Limestone Filler. Mat. Struct. 2016, 49, 2749-2766. [CrossRef]

38. Silva, P.R.; de Brito, J. Experimental study of mechanical properties and shrinkage in self-compacting concrete with binary and ternary mixtures of fly ash and limestone filler, European. J. Environ. Civ. Eng. 2017, 21, 430-453. [CrossRef]

39. Instituto Português da Qualidade-IPQ. NP EN 206-9: Concrete. Part 9: Additional Rules for Self-Compacting Concrete (SCC); IPQ: Lisbon, Portugal, 2010; p. 35.

40. Instituto Português da Qualidade-IPQ. NP EN 12350-8: Testing Fresh Concrete. Part 8: Self-Compacting Concrete, Slump-Flow; IPQ: Lisbon, Portugal, 2010; p. 12.

41. Instituto Português da Qualidade-IPQ. NP EN 12350-9: Testing Fresh Concrete. Part 9: Self-Compacting Concrete, V-Funnel Test; IPQ: Lisbon, Portugal, 2010; p. 11.

42. Instituto Português da Qualidade-IPQ. NP EN 12350-10: Testing Fresh Concrete. Part 10: Self-Compacting Concrete, L-Box Test; IPQ: Lisbon, Portugal, 2010; p. 2.

43. Instituto Português da Qualidade-IPQ. NP EN 12350-12: Testing Fresh Concrete. Part 12: Self-Compacting Concrete, J-Ring Test; IPQ: Lisbon, Portugal, 2012; p. 14.

44. Instituto Português da Qualidade-IPQ. NP EN 12350-11: Testing Fresh Concrete. Part 11: Self-Compacting Concrete, Sieve Segregation Test; IPQ: Lisbon, Portugal, 2011; p. 12.

45. Instituto Português da Qualidade-IPQ. NP EN 12390-7, Testing Hardened Concrete, Part 7: Density of Hardened Concrete; IPQ: Lisbon, Portugal, 2009; p. 14.

46. Instituto Português da Qualidade-IPQ. NP EN 12390-3, Testing Hardened Concrete, Part 3: Compressive Strength of Test Specimens; IPQ: Lisbon, Portugal, 2011; p. 21.

47. Instituto Português da Qualidade-IPQ. NP EN 12390-6 (Ed. 2), Testing Hardened Concrete, Part 6: Tensile Splitting Strength of Test Specimens; IPQ: Lisbon, Portugal, 2011; p. 14.

48. LNEC E 397. Hardened Concrete, Determination of the Modulus of Elasticity of Concrete in Compression (in Portuguese); National Laboratory for Civil Engineering: Lisbon, Portugal, 1993; p. 2.

49. Instituto Português da Qualidade-IPQ. NP EN 12504-4, Testing Concrete, Part 4: Determination of Ultrasonic Pulse Velocity; IPQ: Lisbon, Portugal, 2007; p. 18.

50. DIN 52108. Testing of Inorganic Non-Metallic Materials-Wear Test Using the Grinding Wheel According to Böhme-Grinding Wheel Method; Deutsches Institut für Normung e.V.: Koblenz, Germany, 2010. 
51. LNEC E 398. Hardened Concrete, Determination of Shrinkage and of Swelling; National Laboratory for Civil Engineering: Lisbon, Portugal, 1993; p. 2. (In Portuguese)

52. LNEC E 399. Hardened Concrete, Determination of the Creep in Compression; National Laboratory for Civil Engineering: Lisbon, Portugal, 1993; p. 4. (In Portuguese)

53. Kebaili, O.; Mouret, M.; Arabi, N.; Cassagnabere, F. Adverse effect of the mass substitution of natural aggregates by air-dried recycled concrete aggregates on the self-compacting ability of concrete: Evidence and analysis through an example. J. Clean. Prod. 2015, 87, 752-761. [CrossRef]

54. Pereira-de-Oliveira, L.; Nepomuceno, M.C.S.; Castro-Gomes, J.P.; Vila, M.F.C. Permeability properties of self-compacting concrete with coarse recycled aggregates. Constr. Build. Mater. 2014, 51, 113-120. [CrossRef]

55. Safiuddin, M.; Salam, M.A.; Jumaat, M.Z. Effects of recycled concrete aggregate on the fresh properties of self-consolidating concrete. Arch. Civ. Mech. Eng. 2011, 11, 1023-1041. [CrossRef]

56. Tuyan, M.; Mardani-Aghabaglou, A.; Ramyar, K. Freeze-thaw resistance, mechanical and transport properties of self-consolidating concrete incorporating coarse recycled concrete aggregate. Mater. Des. 2014, 53, $983-991$. [CrossRef]

57. Panda, K.C.; Bal, P.K. Properties of self-compacting concrete using recycled coarse aggregate. Procedia Eng. 2013, 51, 159-164. [CrossRef]

58. Modani, P.O.; Mohitkar, V.M. Self-compacting concrete with recycled aggregate: A solution for sustainable development. Int. J. Civ. Struct. Eng. 2014, 4, 430-440.

59. Kou, S.C.; Poon, C.S. Properties of self-compacting concrete prepared with coarse and fine recycled concrete aggregates. Cem. Concr. Compos. 2009, 31, 622-627. [CrossRef]

60. Uygunoğlu, T.; Topçu, İ.B.; Çelik, A.G. Use of waste marble and recycled aggregates in self-compacting concrete for environmental sustainability. J. Clean. Prod. 2014, 84, 691-700. [CrossRef]

61. Malhotra, V. Testing Hardened Concrete: Non-Destructive Methods; American Concrete Institute: Farmington Hills, MI, USA, 1976.

62. Barbudo, A.; de Brito, J.; Evangelista, L.; Bravo, M.; Agrela, F. Influence of water-reducing admixtures on the mechanical performance of recycled concrete. J. Clean. Prod. 2013, 59, 93-98. [CrossRef]

63. Lotfi, S.; Eggimann, M.; Wagner, E.; Mróz, R.; Deja, J. Performance of recycled aggregate concrete based on a new concrete recycling technology. Constr. Build. Mater. 2015, 95, 243-256. [CrossRef]

64. Pereira, P.; Evangelista, L.; de Brito, J. The effect of superplasticizers on the mechanical performance of concrete made with fine recycled concrete aggregates. Cem. Concr. Compos. 2012, 34, 1044-1052. [CrossRef]

65. Cartuxo, F.; Brito J de Evangelista, L.; Jiménez, J.R.; Ledesma, E.F. Increased Durability of Concrete Made with Fine Recycled Concrete Aggregates Using Superplasticizers. Materials 2016, 9, 98. [CrossRef]

66. Evangelista, L.; de Brito, J. Concrete with Fine Recycled Aggregates: A Review. Eur. J. Environ. Civ. Eng. 2014, 18, 129-172. [CrossRef]

67. Manzi, S.; Mazzotti, C.; Bignozzi, M. Short and long-term behavior of structural concrete with recycled concrete aggregate. Cem. Concr. Compos. 2013, 37, 312-318. [CrossRef]

68. Domingo-Cabo, A.; Lázaro, C.; López-Gyarre, F.; Serrano-López, M.A.; Serna, P.; Castaño-Tabares, J.O. Creep and shrinkage of recycled aggregate concrete. Constr. Build. Mater. 2009, 23, 2545-2553. [CrossRef]

(C) 2019 by the authors. Licensee MDPI, Basel, Switzerland. This article is an open access article distributed under the terms and conditions of the Creative Commons Attribution (CC BY) license (http://creativecommons.org/licenses/by/4.0/). 